\title{
Total Synthesis of (-)-Hennoxazole
}

Thomas E. Smith,* Wen-Hsin Kuo, Victoria D. Bock, Jennifer L. Roizen, Emily P. Balskus, and Ashleigh B. Theberge

Department of Chemistry, Williams College, Williamstown, Massachusetts 01267

\section{Supporting Information}

General Information. Oxygen- or moisture-sensitive reactions were carried out in flame-dried or ovendried glassware sealed with rubber septa under a positive pressure of dry nitrogen. Similarly sensitive liquids and solutions were transferred by gas-tight syringe or canula. Unless indicated otherwise, reagents and solvents were purchased and used without purification. Ether, THF, and $\mathrm{CH}_{2} \mathrm{Cl}_{2}, \mathrm{were}$ purified by passage through a bed of activated alumina. ${ }^{1}$ Analytical TLC was performed with $0.25 \mathrm{~mm}$ silica gel 60 plates with $254 \mathrm{~nm}$ fluorescent indicator from SiliCycle. Plates were visualized under UV light and treatment with either acidic $p$-anisaldehyde stain or aqueous ceric ammonium molybdate solution followed by gentle heating. The term flash chromatography refers to preparative silica gel column chromatography as described by Still and co-workers. ${ }^{2}$ Automated chromatography was accomplished using an Isco Combiflash System Sg 100c. Silica gel 60, 230-240 mesh, was purchased from SiliCycle (R10030B). Analytical high performance liquid chromatography (HPLC) was carried out on an Agilent 1100 chromatograph equipped with a variable wavelength detector. ${ }^{1} \mathrm{H}$ NMR spectra were recorded on a Brüker Avance $500(500 \mathrm{MHz})$ spectrometer and are reported in ppm using tetramethylsilane $(0.00 \mathrm{ppm})$ or solvent $\left(\mathrm{CDCl}_{3}: 7.24 \mathrm{ppm}\right.$; acetone- $\left.\mathrm{d}_{6}: 2.04 \mathrm{ppm}\right)$ as an internal standard. Data are reported as $(\mathrm{ap}=$ apparent, $\mathrm{s}=$ singlet, $\mathrm{d}=$ doublet, $\mathrm{t}=$ triplet, $\mathrm{q}=$ quartet, $\mathrm{m}=$ multiplet, $\mathrm{b}=$ broad; coupling constant(s) in $\mathrm{Hz}$; integration. Proton-decoupled ${ }^{13} \mathrm{C}$ NMR spectra were recorded at $125 \mathrm{MHz}$ and are reported in ppm using solvent as an internal standard $\left(\mathrm{CDCl}_{3}: 77.00 \mathrm{ppm}\right.$, acetone- $\mathrm{d}_{6}: 206.00 \mathrm{ppm}$ ). Infrared spectra were recorded as thin films on $\mathrm{NaCl}$ plates on a Perkin-Elmer 710 Series Fourier transform spectrometer (FTIR). Melting points were determined with a Laboratory Devices Mel-Temp II apparatus equipped with an Fluke Model $51 \mathrm{~K} / \mathrm{J}$ thermocouple and are uncorrected. Optical rotations were measured on a Perkin-Elmer 241 digital polarimeter using the sodium (589, D line) lamp and are reported as follows: $[\alpha]_{\lambda}{ }^{\mathrm{T}}{ }^{\circ} \mathrm{C}(\mathrm{c}=\mathrm{g} / 100 \mathrm{~mL}$, solvent). Combustion analyses were performed by Atlantic Microlab, Norcross, Georgia. High Resolution mass spectra (HRMS) were recorded at the Nebraska Center for Mass Spectrometry or at the University of Hawaii, Manoa.

(1) Pangborn, A. B.; Giardello, M. A.; Grubbs, R. H.; Rosen, R. K.; Timmers, F. J. Organometallics $1996,1518$.

(2) Still, W. C.; Kahn, M.; Mitra, A. J. Org. Chem 1978, 43, 2923. 


\section{$(Z, 3 R, 4 S)$-2,4-dimethylhepta-1,5-dien-3-ol (4) ${ }^{3}$}
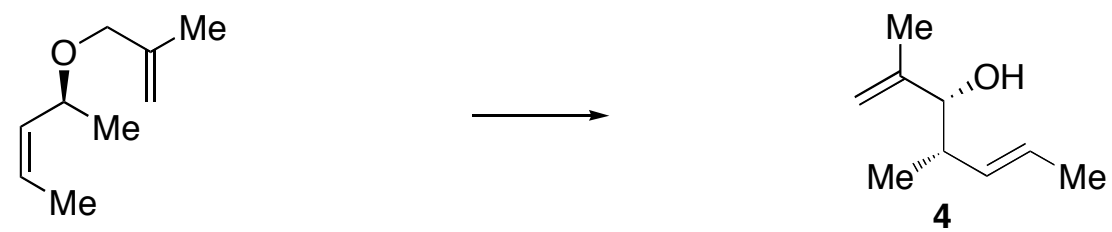

Following the procedure reported by Williams, ${ }^{3}$ a $9: 1$ mixture of syn:anti products was obtained. Chiral gc (Chiraldex G-TA column, $30 \mathrm{~m}$ x $0.25 \mathrm{~mm}, 30 \mathrm{psi} \mathrm{He}, 50{ }^{\circ} \mathrm{C}, 1{ }^{\circ} \mathrm{C} / \mathrm{min} \mathrm{ramp}$ ) indicated the syn diastereomer to be present in $95.4 \%$ ee but the anti diastereomer to be present in only $72.2 \%$ ee. The minor anti material was removed by chromatography on silver nitrate-impregnated silica gel ${ }^{4}$ to give pure title compound 4 as a colorless oil: ${ }^{1} \mathrm{H}$ NMR $\left(500 \mathrm{MHz}, \mathrm{CDCl}_{3}\right) \delta 5.51(\mathrm{dq}, J=15.4,6.4 \mathrm{~Hz}, 1 \mathrm{H})$, 5.40 (ddq, $J=15.3,7.1,1.2 \mathrm{~Hz}, 1 \mathrm{H}), 4.95$ (s, 1H), 4.88 (s, 1H), 3.90 (dd, J = 4.5, $4.4 \mathrm{~Hz}, 1 \mathrm{H}$ ), 2.36 (dq, $J=12.8,6.7 \mathrm{~Hz}, 1 \mathrm{H}), 1.71(\mathrm{~s}, 3 \mathrm{H}), 1.68(\mathrm{~d}, 3 \mathrm{H}, J=6.2 \mathrm{~Hz}), 1.56(\mathrm{~d}, J=3.7 \mathrm{~Hz}, 1 \mathrm{H}), 0.98(\mathrm{~d}, J=6.9$ $\mathrm{Hz}, 3 \mathrm{H}) ;{ }^{13} \mathrm{C} \mathrm{NMR}\left(125 \mathrm{MHz}, \mathrm{CDCl}_{3}\right) \delta$ 145.9, 133.6, 125.3, 111.6, 78.8, 39.7, 18.6, 18.1, 14.2 ppm.; IR (film) 3403, 2970, 2920, 2877, 1652, 1452, 1376, 1295, 1115, 1023, 981, 898, $557 \mathrm{~cm}^{-1} \cdot[\alpha]_{\mathrm{D}}{ }^{24}=+5.4^{\circ}$ $\left(c=1.01, \mathrm{CHCl}_{3}\right)$. HRMS (EI): Exact mass calcd for $\mathrm{C}_{9} \mathrm{H}_{16} \mathrm{O}[\mathrm{M}]^{+}:$140.1201; Found: 140.1192.

(3) Williams, D. R.; Brooks, D. A.; Berliner, M. A. J. Am. Chem. Soc. 1999, 121, 4924-4925.

(4) Li, T-S.; Li, J-T.; Li, H-Z J. Chromatogr. A 1995, 715, 372. 


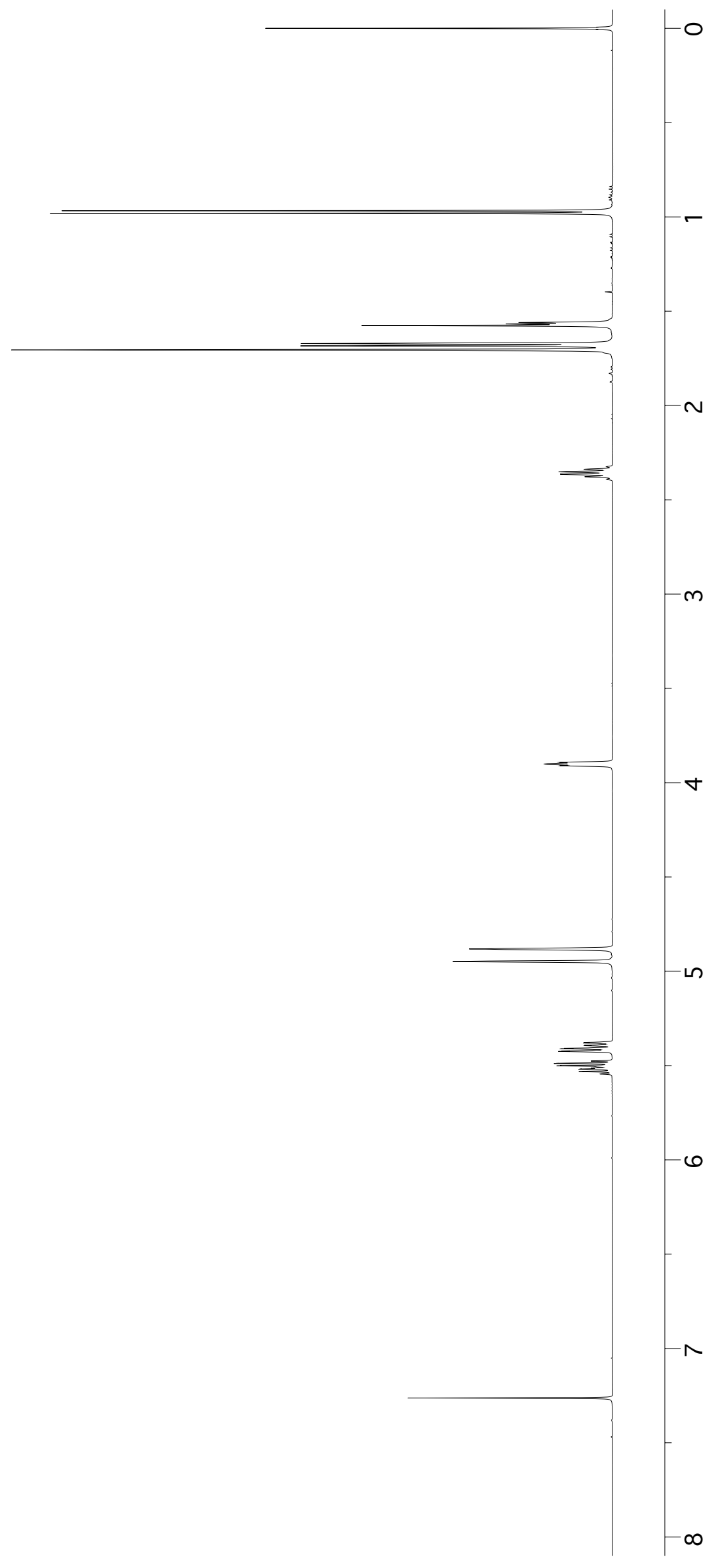




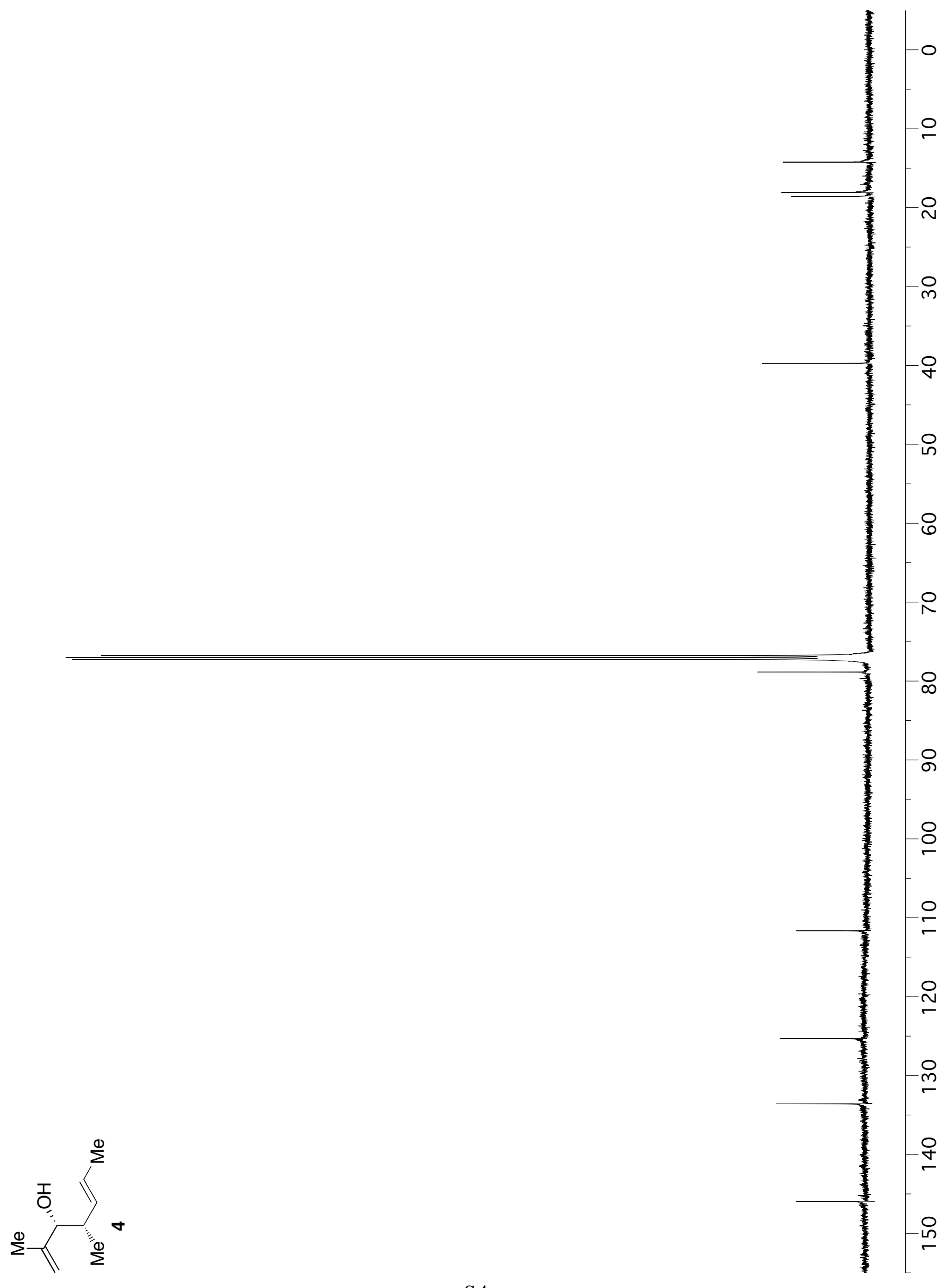




\section{$(S, 3 Z, 6 Z)-3,5-d i m e t h y l o c t a-3,6-d i e n-1-o l(5)^{3}$}
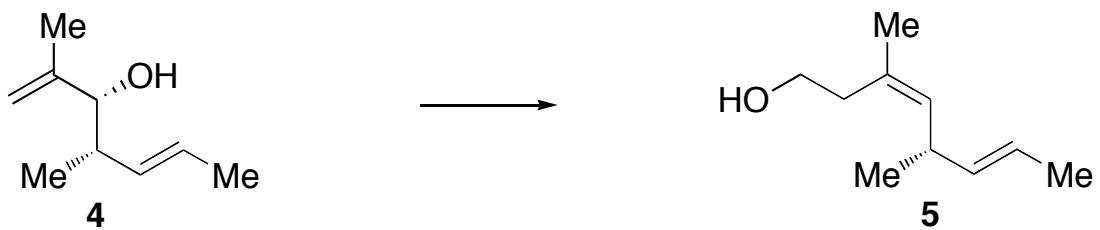

The following procedure was adapted from Still ${ }^{5}$ and van Boom ${ }^{6}$ (Title compound 5 has also been prepared by Williams by a different route). ${ }^{3}$ To a $10 \mathrm{~mL}$ concentration flask was added $\mathrm{KH}$ ( $290 \mathrm{mg}$ of a $35 \%$ dispersion in mineral oil, $2.383 \mathrm{mmol}, 2.2$ equiv). The white solid was washed in dry pentanes $(3 \mathrm{x}$ $5 \mathrm{~mL})$ and suspended in dry THF $(2 \mathrm{~mL})$ at $0{ }^{\circ} \mathrm{C}$. To this suspension was added allylic alcohol $4(152$ $\mathrm{mg}, 1.083 \mathrm{mmol}, 1$ equiv) via cannula in THF $(1.2 \mathrm{~mL})$, producing a cloudy yellow solution. Dibenzo -18-crown-6 (catalytic amt) was added as a white powder, followed by addition of $\mathrm{Bu}_{3} \mathrm{SnCH}_{2} \mathrm{I}^{7}(560 \mathrm{mg}$, $1.300 \mathrm{mmol}, 1.2$ equiv) via cannula in THF $(0.8 \mathrm{~mL})$. The solution became a light brown color and was warmed to rt. After $2 \mathrm{~h}$, the solution was cooled to $-78{ }^{\circ} \mathrm{C}$. $n$-Butyllithium $(1.1 \mathrm{~mL}$ of a $1.56 \mathrm{M}$ in hexanes, $1.625 \mathrm{mmol}, 1.5$ equiv) was added dropwise via syringe down the cold wall of the flask, forming an orange solution. The solution was stirred at $-78{ }^{\circ} \mathrm{C}$ for $2 \mathrm{~h}$. The orange color gradually changed to a light brown and then became more yellow. The reaction mixture was partitioned between $\mathrm{Et}_{2} \mathrm{O}(10 \mathrm{~mL})$ and sat aq $\mathrm{NH}_{4} \mathrm{Cl}(10 \mathrm{~mL})$, and the layers were separated. The aqueous layer was extracted with $\mathrm{Et}_{2} \mathrm{O}(2 \times 10 \mathrm{~mL})$, and the combined organic layers were dried over $\mathrm{Na}_{2} \mathrm{SO}_{4}$, filtered, and concentrated in vacuo to yield a clear, yellow oil and a red-brown precipitate. The product was purified via automated silica column chromatography $(0 \rightarrow 15 \%$ EtOAc/hexanes over $30 \mathrm{~min}, 110 \mathrm{~g}$ column; TLC: $\mathrm{R}_{\mathrm{f}}=0.42$ in $15 \%$ EtOAc/hexanes, anisaldehyde stain) to provide homoallylic alcohol 5 (0.138 g, $83 \%$ yield) as a clear, colorless oil. Due to the volatility of alcohol $\mathbf{5}$, it should not be exposed to pressures lower than $5 \mathrm{~mm} \mathrm{Hg}$. Chiral gc (Chiraldex G-TA column, $30 \mathrm{~m} \mathrm{x} 0.25 \mathrm{~mm}, 30 \mathrm{psi} \mathrm{He}, 50{ }^{\circ} \mathrm{C}$, $0.6{ }^{\circ} \mathrm{C} / \mathrm{min}$ ramp) was not able to completely resolve a racemic sample, but was consistent with a product ee identical to that of the starting material ee of $95 \%$ ( $\geq 90 \%$ ee is the best confidence that can be estimated from the poorly resolved peaks) : ${ }^{1} \mathrm{H}$ NMR $\left(500 \mathrm{MHz}, \mathrm{CDCl}_{3}\right) \delta 5.45-5.34(\mathrm{~m}, 2 \mathrm{H}), 5.18(\mathrm{~d}$, $1 \mathrm{H}, J=9.6 \mathrm{~Hz}), 3.72-3.62(\mathrm{~m}, 2 \mathrm{H}), 3.12-3.03(\mathrm{~m}, 1 \mathrm{H}), 2.37(\mathrm{dt}, J=13.4,6.4 \mathrm{~Hz}, 1 \mathrm{H}), 2.30(\mathrm{dt}, J=13.4$, $6.4 \mathrm{~Hz}, 1 \mathrm{H}), 1.72(\mathrm{~d}, 3 \mathrm{H}, J=1.2 \mathrm{~Hz}), 1.64(\mathrm{~d}, J=4.7 \mathrm{~Hz}, 3 \mathrm{H}), 1.34(\mathrm{br} \mathrm{s}, 1 \mathrm{H}), 1.01(\mathrm{~d}, J=6.7 \mathrm{~Hz}, 3 \mathrm{H})$ ppm; ${ }^{13} \mathrm{C}$ NMR (125 MHz, $\left.\mathrm{CDCl}_{3}\right) \delta$ 136.3, 133.2, 129.7, 122.8, 60.7, 35.4, 35.3, 23.5, 21.7, 17.9 ppm; IR (film) 3325, 2963, 2870, 1449, 1377, 1042, 968, $868 \mathrm{~cm}^{-1} ;[\alpha]_{\mathrm{D}^{24}}=-59.3^{\circ}\left(c=1.00, \mathrm{CHCl}_{3}\right)$. HRMS

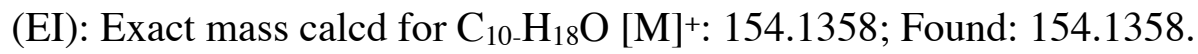

(5) Still, W. C.; Mitra, A. J. Am. Chem. Soc. 1978, 100, 1927-1928.

(6) Ovaa, H.; Lastdrager, B.; Codée, J. D. C.; van der Marel, G. A.; Overkleeft, H. S.; van Boom, J. H. J. Chem. Soc., Perkin Trans. 1 2002, 2370-2377.

(7) (a) Seyferth, D.; Andrews, S. B. J. Organomet. Chem. 1971, 30, 151-152. (b) Still, W. C. J. Am. Chem. Soc. 1978, 100, 1481-1486. 


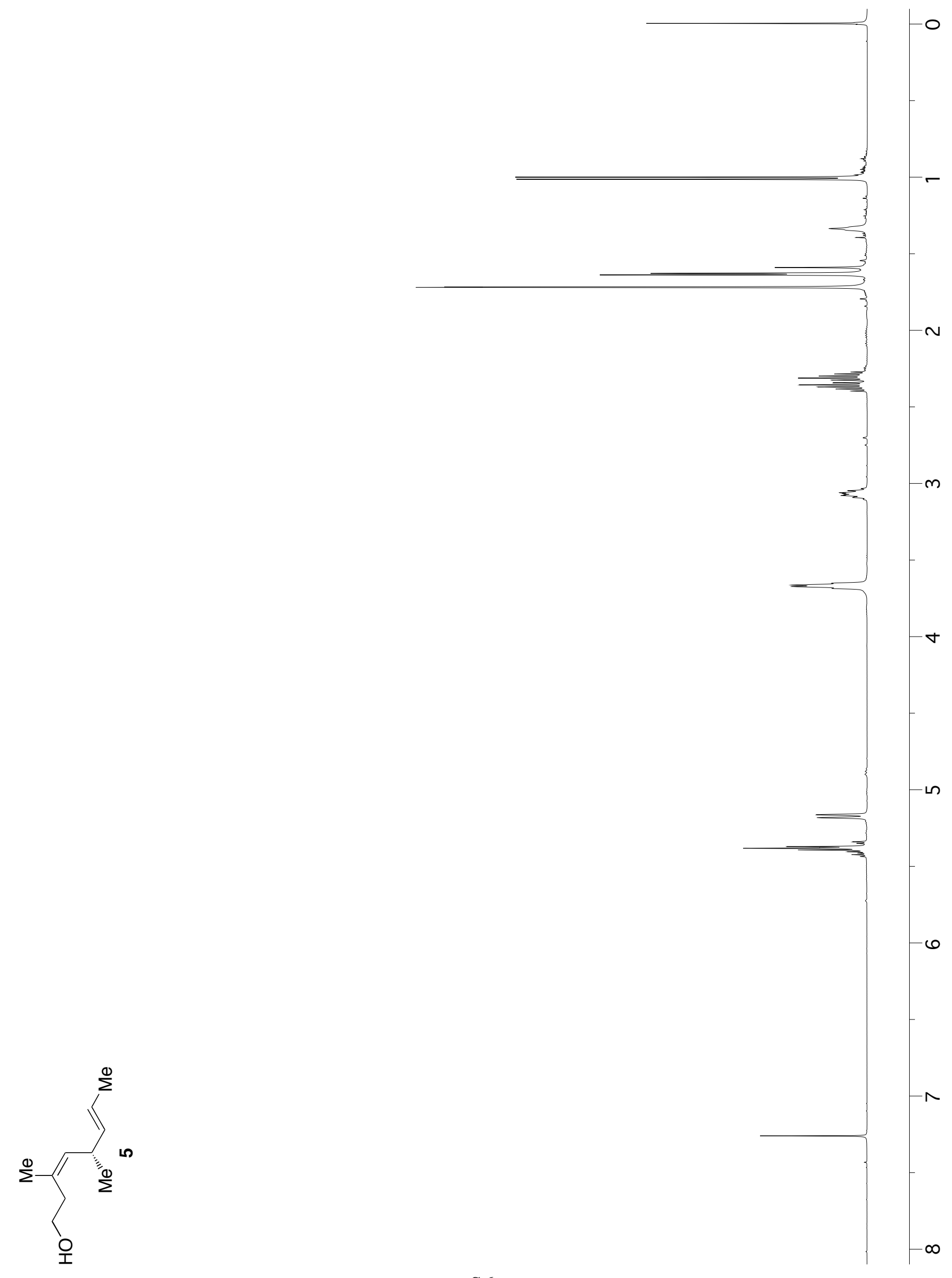




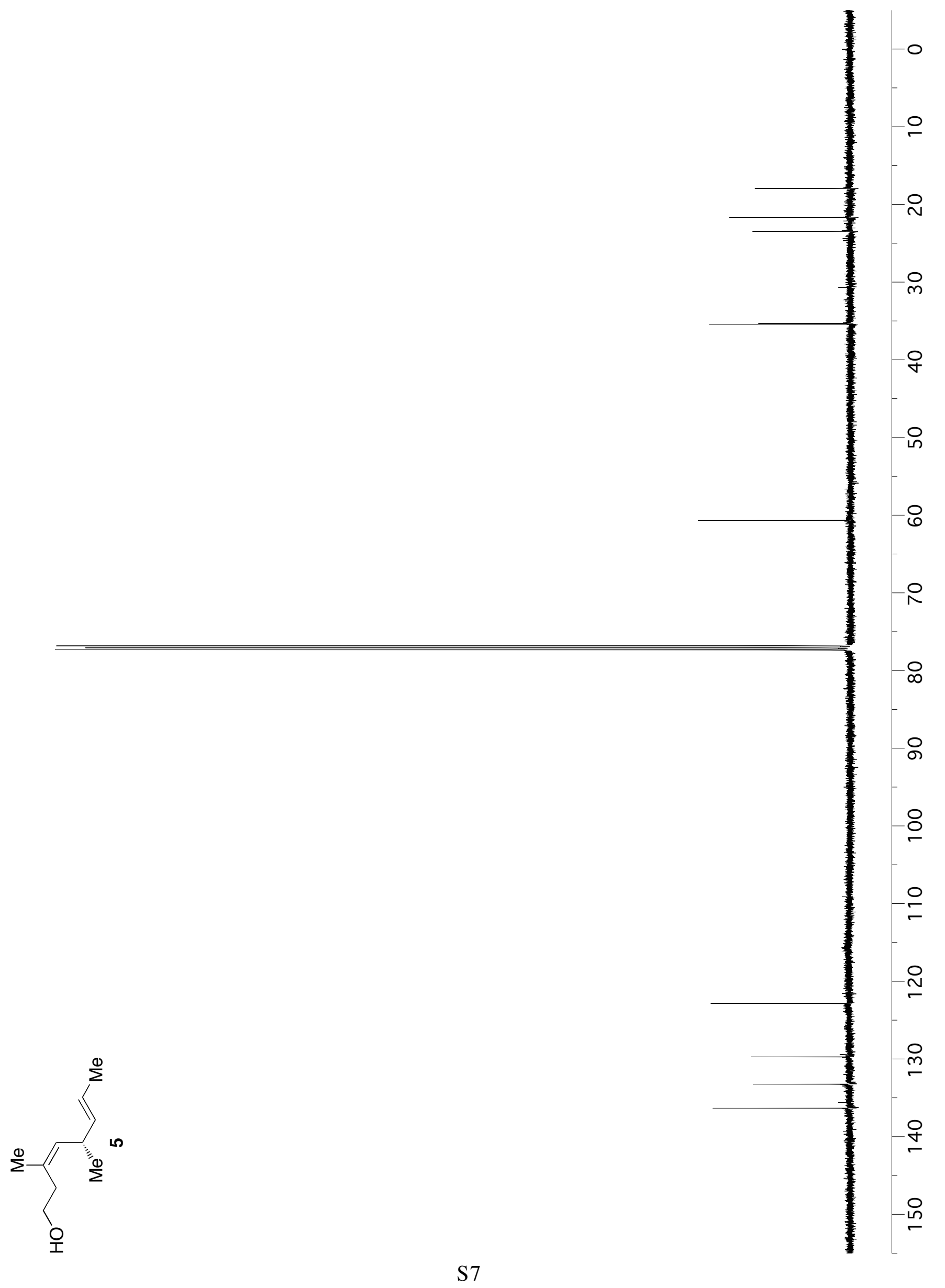




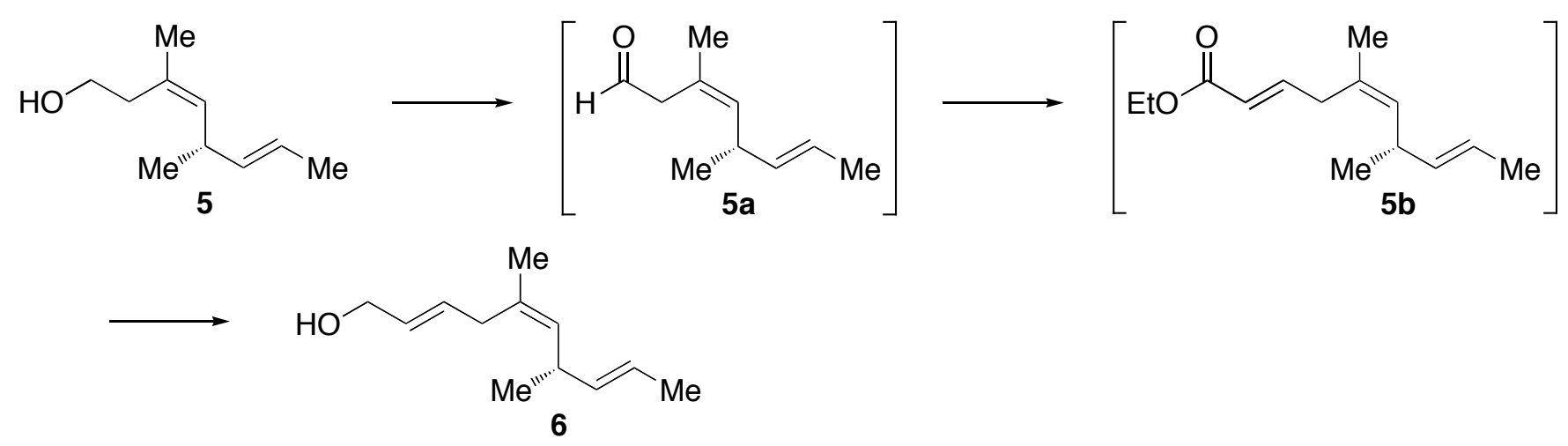

The following procedure was adapted from Parrain ${ }^{8}$ and Wavrin. ${ }^{9}$ A $25 \mathrm{~mL}$ concentration flask containing alcohol 5 (92.9 mg, $0.602 \mathrm{mmol}, 1$ equiv) in dry $\mathrm{CH}_{2} \mathrm{Cl}_{2}(6 \mathrm{~mL})$ was cooled to $0{ }^{\circ} \mathrm{C}$. DessMartin Periodinane (DMP) (0.332 g, $0.783 \mathrm{mmol}, 1.3$ equiv) was added, and the solution became a cloudy white. After $5 \mathrm{~min}$, the solution was warmed to rt. After $1 \mathrm{~h}$, a 1:1 mixture of sat aq $\mathrm{Na}_{2} \mathrm{~S}_{2} \mathrm{O}_{4}$ and sat aq $\mathrm{NaHCO}_{3}(12 \mathrm{~mL})$ was added to the crude mixture which was then stirred vigorously for 15 minutes. The layers were separated, and the aqueous layer was extracted with $\mathrm{CH}_{2} \mathrm{Cl}_{2}(2 \times 12 \mathrm{~mL})$. The combined organics were washed with sat aq $\mathrm{NaHCO}_{3}(5 \mathrm{~mL})$, dried over $\mathrm{Na}_{2} \mathrm{SO}_{4}$, filtered, and concentrated in vacuo to give a light yellow oil with a white precipitate. The residue was suspended in $20 \% \mathrm{Et}_{2} \mathrm{O} /$ pentane $(5 \mathrm{~mL})$ and filtered through a small plug of Celite (additional $5 \mathrm{~mL}$ rinse). The solvent was removed in vacuo to provide (S,3Z,6Z)-3,5-dimethylocta-3,6-dienal (5a) (0.116 g, with DMP contaminants) as a light yellow oil (TLC: $\mathrm{R}_{\mathrm{f}}=0.82,15 \%$ EtOAc/hexanes, anisaldehyde stain) which was carried on without further purification. Due to the volatility of aldehyde $\mathbf{5 a}$, it should not be exposed to pressures lower than $5 \mathrm{~mm} \mathrm{Hg}:{ }^{1} \mathrm{H}$ NMR $\left(500 \mathrm{MHz}, \mathrm{CDCl}_{3}\right) \delta 9.57(\mathrm{t}, 1 \mathrm{H}, J=2.4 \mathrm{~Hz}), 5.42$ $-5.34(\mathrm{~m}, 2 \mathrm{H}), 5.32(\mathrm{~d}, 1 \mathrm{H}, J=10.2 \mathrm{~Hz}), 3.12(\mathrm{~d}, 2 \mathrm{H}, J=2.4 \mathrm{~Hz}), 2.95(\mathrm{ddq}, 1 \mathrm{H}, J=10.2,9.1,6.8 \mathrm{~Hz})$, $1.76(\mathrm{~d}, 3 \mathrm{H}, J=1.3 \mathrm{~Hz}), 1.64(\mathrm{~d}, 3 \mathrm{H}, J=5.6 \mathrm{~Hz}), 1.03(\mathrm{~d}, 3 \mathrm{H}, J=6.8 \mathrm{~Hz}) \mathrm{ppm} ;{ }^{13} \mathrm{C}$ NMR $(125 \mathrm{MHz}$, $\mathrm{CDCl}_{3}$ ) $\delta$ 199.5, 135.3, 134.8, 124.7, 123.3, 47.5, 35.8, 24.4, 21.4, 17.8 ppm; IR (film) 3022, 2966, $2927,2870,2717,1726,1450,1379,1238,1170,1120,1048,1017,970,857 \mathrm{~cm}^{-1}$.

The following procedure was adapted from Lee. ${ }^{10}$ To a $10 \mathrm{~mL}$ concentration flask was added $\mathrm{NaH}$ ( $0.048 \mathrm{~g}$ of a $60 \%$ dispersion in oil, $1.205 \mathrm{mmol}, 2.0$ equiv). The white solid was washed in dry pentanes $(3 \times 1 \mathrm{~mL})$ and suspended in dry THF $(0.4 \mathrm{~mL})$. To this suspension was added triethylphosphonoacetate ( $0.251 \mathrm{~mL}, 1.265 \mathrm{mmol}, 2.1$ equiv) dropwise via syringe, and the solid dissolved to give a light yellow solution. After $1 \mathrm{hr}$, the solution was cooled to $0{ }^{\circ} \mathrm{C}$, and unpurified aldehyde $\mathbf{5 a}$ (theoretical from above, $2.390 \mathrm{mmol}, 1$ equiv) was added via cannula in dry THF $(0.5 \mathrm{~mL})$, producing a bright yellow/orange solution. After $30 \mathrm{~min}$, the solution was warmed to rt and after an additional $30 \mathrm{~min}$, sat aq $\mathrm{NH}_{4} \mathrm{Cl}(20$ $\mathrm{mL})$ was added along with $\mathrm{Et}_{2} \mathrm{O}(20 \mathrm{~mL})$, and the layers were separated. The aqueous layer was further extracted with $\mathrm{Et}_{2} \mathrm{O}(2 \times 10 \mathrm{~mL})$, and the combined organic layers were dried over $\mathrm{Na}_{2} \mathrm{SO}_{4}$, filtered, and concentrated in vacuo to yield (S,2E,5Z,8Z)-ethyl 5,7-dimethyldeca-2,5,8-trienoate (5b) $(0.270 \mathrm{~g}$, with phosphate contaminants) as a clear, yellow oil (TLC: $R_{\mathrm{f}}=0.80$ in $20 \%$ EtOAc/hexanes, anisaldehyde stain) which was carried on without further purification. Due to the volatility of ethyl ester $\mathbf{5 b}$, it should not be exposed to pressures lower than $5 \mathrm{~mm} \mathrm{Hg}:{ }^{1} \mathrm{H} \mathrm{NMR}\left(500 \mathrm{MHz}, \mathrm{CDCl}_{3}\right) \delta 6.90(\mathrm{dt}, 1 \mathrm{H}, J=15.6$, $6.7 \mathrm{~Hz}), 5.82(\mathrm{dt}, 1 \mathrm{H}, J=15.6,1.4 \mathrm{~Hz}), 5.41-5.31(\mathrm{~m}, 2 \mathrm{H}), 5.12(\mathrm{~d}, 1 \mathrm{H}, J=9.3 \mathrm{~Hz}), 4.18(\mathrm{q}, 2 \mathrm{H}, J=7.1$

(8) Commeiras, L.; Santelli, M.; Parrain, J.-L. Org. Lett. 2001, 3, 1713-1715.

(9) Wavrin, L.; Viala, J. Synthesis 2002, 3, 326-330.

(10) Lee, E.; Shin, I.-J.; Kim, T.-S. J. Am. Chem. Soc. 1990, 112, 260-264. 
$\mathrm{Hz}), 2.95(\mathrm{dd}, 2 \mathrm{H}, J=6.7,2.0 \mathrm{~Hz}), 2.90(\mathrm{~m}, 1 \mathrm{H}), 1.68(\mathrm{~d}, 3 \mathrm{H}, J=1.0 \mathrm{~Hz}), 1.63(\mathrm{~d}, 3 \mathrm{H}, J=5.0 \mathrm{~Hz}), 1.28$ $(\mathrm{t}, 3 \mathrm{H}, J=7.1 \mathrm{~Hz}), 1.01(\mathrm{~d}, 3 \mathrm{H}, J=6.8 \mathrm{~Hz}) \mathrm{ppm} ;{ }^{13} \mathrm{C} \mathrm{NMR}\left(125 \mathrm{MHz}, \mathrm{CDCl}_{3}\right) \delta 166.6,146.4,135.7$, 132.3, 129.7, 123.0, 122.0, 60.2, 35.6, 35.0, 23.5, 21.4, 17.9, 14.3 ppm; IR (film) 3022, 2966, 2927, $2870,2717,1725,1450,1379,1048,970,857 \mathrm{~cm}^{-1}$.

The following procedure was adapted from Fernandes. ${ }^{11}$ To a $50 \mathrm{~mL}$ concentration flask containing ethyl ester $\mathbf{5 b}$ as an unpurified mixture (theoretical from above, $2.390 \mathrm{mmol}, 1$ equiv) in dry $\mathrm{CH}_{2} \mathrm{Cl}_{2}(8.6 \mathrm{~mL}$ ) at $0{ }^{\circ} \mathrm{C}$ was added DIBAL-H $\left(1.99 \mathrm{~mL}\right.$ of a $1.0 \mathrm{M}$ solution in $\mathrm{CH}_{2} \mathrm{Cl}_{2}, 1.987 \mathrm{mmol}, 3.3$ equiv) dropwise via syringe. Some gas evolution was evident. After $1 \mathrm{hr}$, half-saturated Rochelle's salt $(20 \mathrm{~mL})$ and $\mathrm{Et}_{2} \mathrm{O}$ $(20 \mathrm{~mL})$ was added and the mixture stirred vigorously overnight and allowed to come to rt. The layers were separated and the aqueous layer was further extracted with $\mathrm{Et}_{2} \mathrm{O}(3 \times 25 \mathrm{~mL})$. The combined organic layers were dried over $\mathrm{Na}_{2} \mathrm{SO}_{4}$, filtered, and concentrated in vacuo to yield a clear, yellow oil. The product was purified via automated silica column chromatography $(0 \rightarrow 15 \%$ EtOAc/hexanes, $10 \mathrm{~g}$ column; TLC: $\mathrm{R}_{\mathrm{f}}=0.28$ in $20 \% \mathrm{EtOAc} /$ hexanes, CAM stain) to provide title alcohol $\mathbf{6}(0.0827 \mathrm{~g}, 76 \%$ yield for three steps) as a clear, colorless oil. Due to the volatility of alcohol $\mathbf{6}$, it should not be exposed to pressures lower than $5 \mathrm{~mm} \mathrm{Hg}$ for more than several hours. When left overnight at $0.5 \mathrm{~mm} \mathrm{Hg}$ for characterization purposes, partial product loss was observed: ${ }^{1} \mathrm{H}$ NMR $\left(500 \mathrm{MHz}, \mathrm{CDCl}_{3}\right) \delta$ 5.70-5.60 (m, 2H), 5.42-5.33 (m, 2H), $5.04(\mathrm{~d}, 1 \mathrm{H}, J=9.4 \mathrm{~Hz}), 4.13-4.07(\mathrm{~m}, 2 \mathrm{H}), 3.05-2.97(\mathrm{~m}, 1 \mathrm{H}), 2.82-2.69$ $(\mathrm{m}, 2 \mathrm{H}), 1.67(\mathrm{~d}, 3 \mathrm{H}, J=1.4 \mathrm{~Hz}), 1.64(\mathrm{~d}, J=3.9 \mathrm{~Hz}, 3 \mathrm{H}), 1.33(\mathrm{br} \mathrm{s}, 1 \mathrm{H}), 1.01(\mathrm{~d}, 3 \mathrm{H}, J=6.7 \mathrm{~Hz})$ ppm; ${ }^{13} \mathrm{C}$ NMR $\left(125 \mathrm{MHz}, \mathrm{CDCl}_{3}\right) \delta 136.1,131.6,130.9,130.5,129.9,122.7,63.7,35.4,35.0,23.4$, 21.5, 17.9 ppm; IR (film) 3325, 2963, 2870, 1449, 1377, 1042, 968, $868 \mathrm{~cm}^{-1} ;[\alpha]_{\mathrm{D}^{24}}=-80.6^{\circ}(c=1.00$, $\mathrm{CHCl}_{3}$ ); Anal calcd for $\mathrm{C}_{12} \mathrm{H}_{20} \mathrm{O}: \mathrm{C}, 79.94 \%, \mathrm{H}, 11.18 \%$; Found: $\mathrm{C}, 79.72 \%, \mathrm{H}, 11.35 \%$. HRMS (EI): Exact mass calcd for $\mathrm{C}_{12} \mathrm{H}_{20} \mathrm{O}[\mathrm{M}]^{+}$: 180.1514; Found: 180.1514 .

(11) Fernandes, R. A.; Bodas, M. S.; Kumar, P. Tetrahedron, 2002, 58, 1223-1227. 


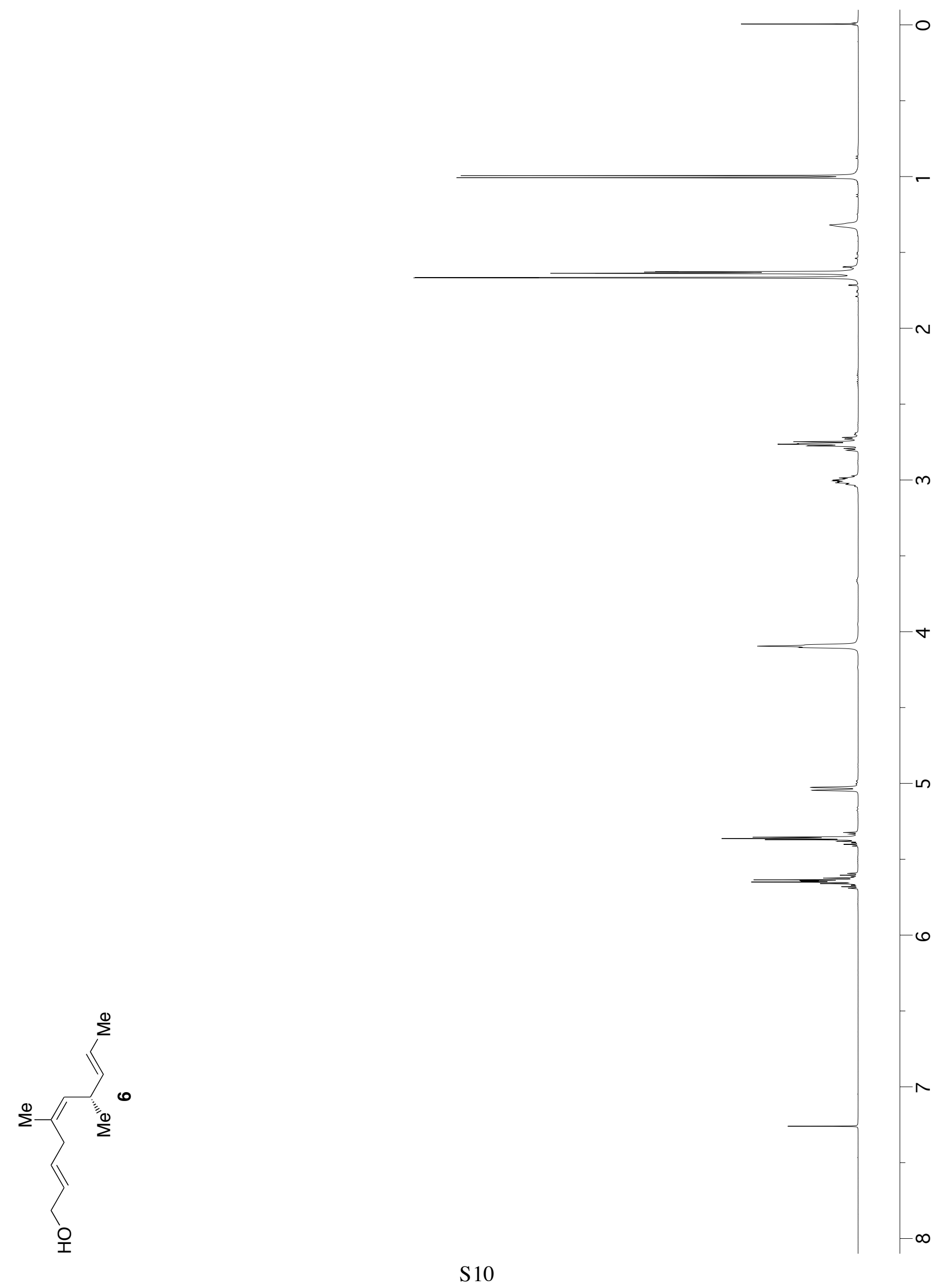




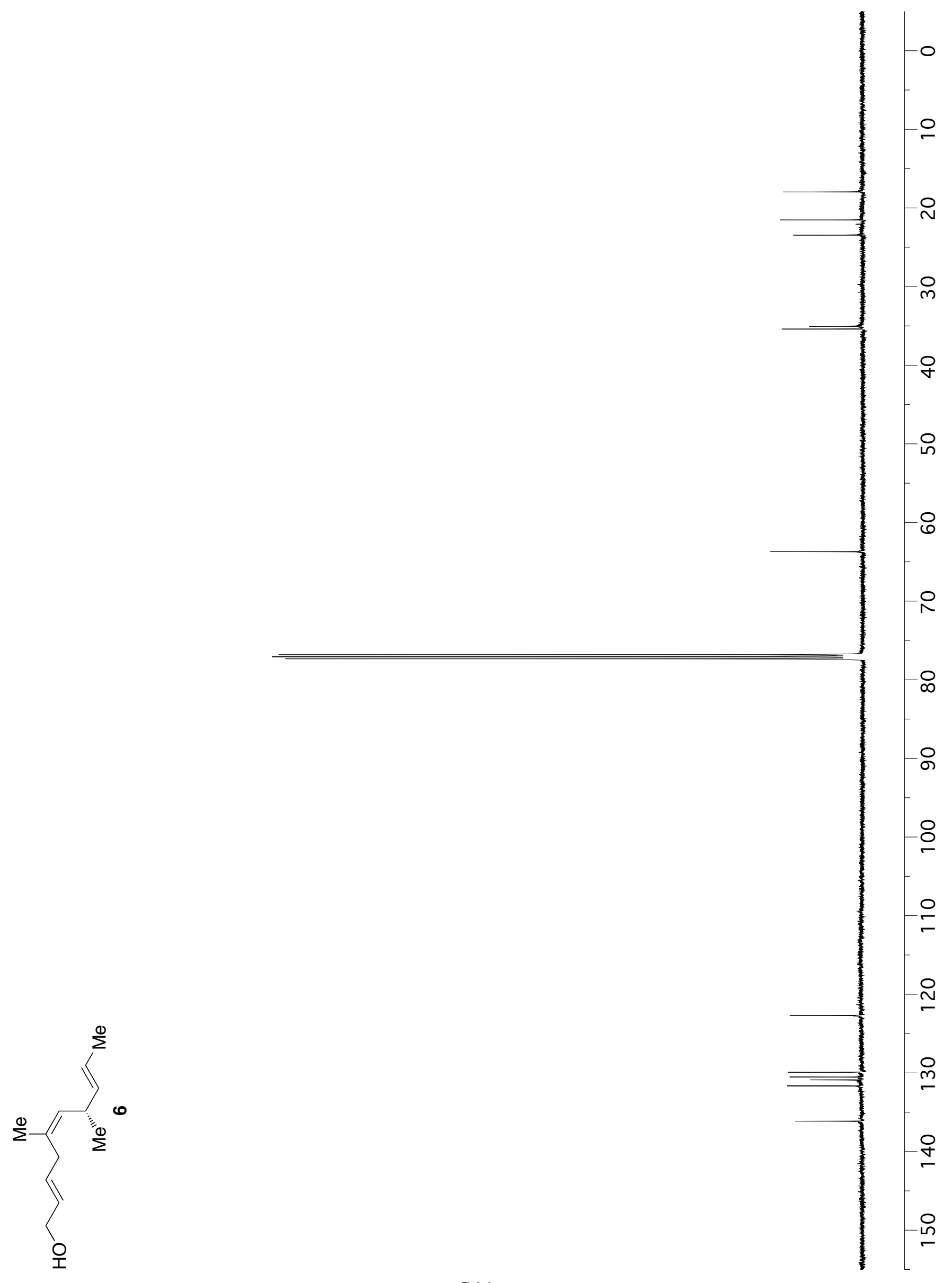




\section{$(S, 2 E, 5 Z, 8 Z)$-1-bromo-5,7-dimethyldeca-2,5,8-triene (3)}
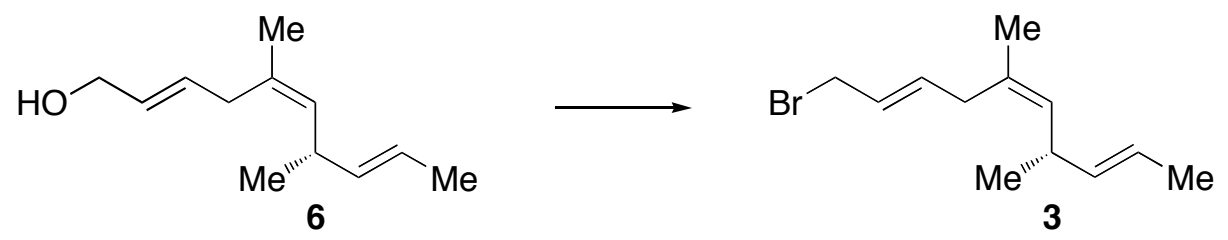

The following procedure was adapted from Corey. ${ }^{12}$ To a $25 \mathrm{~mL}$ concentration flask containing alcohol 6 (0.0818 g, $0.454 \mathrm{mmol}, 1$ equiv) in dry THF $(2 \mathrm{~mL})$ was added $\mathrm{Et}_{3} \mathrm{~N}(0.253 \mathrm{~mL}, 1.815 \mathrm{mmol}, 4$ equiv). The solution was cooled to $-40{ }^{\circ} \mathrm{C}$ and $\mathrm{MsCl}(0.105 \mathrm{~mL}, 1.361 \mathrm{mmol}, 3$ equiv) was added dropwise. A white precipitate formed immediately. After $50 \mathrm{~min}$. at $-40{ }^{\circ} \mathrm{C}$, the suspension was warmed to $0{ }^{\circ} \mathrm{C}$. After $30 \mathrm{~min}$, a solution of $\mathrm{LiBr}(0.394 \mathrm{~g}, 4.540 \mathrm{mmol}, 10$ equiv) in THF $(4 \mathrm{~mL})$ was added dropwise via canula. After $30 \mathrm{~min}$, the flask was warmed to rt. And stirred for an additional $30 \mathrm{~min}$. The reaction was quenched with ice-cold sat. aq. $\mathrm{NaHCO}_{3}(15 \mathrm{~mL})$ and diluted with pentane $(5 \mathrm{~mL})$. The layers were separated and the aqueous layer was further extracted with pentane $(3 \times 10 \mathrm{~mL})$. The combined organic layers were dried over $\mathrm{Na}_{2} \mathrm{SO}_{4}$, filtered, and concentrated in vacuo to yield a clear, yellow oil. The product was purified via automated silica column chromatography (pentane, $4 \mathrm{~g}$ column (TLC: $\mathrm{R}_{\mathrm{f}}=0.89$ in $20 \% \mathrm{EtOAc/hexanes,} \mathrm{anisaldehyde} \mathrm{stain)} \mathrm{to} \mathrm{provide} \mathrm{bromide} \mathbf{3}(0.0958 \mathrm{~g}, 87 \%$ yield) as a clear, colorless oil. Due to the volatility of bromide 3, it should not be exposed to pressures lower than $5 \mathrm{~mm}$ $\mathrm{Hg}$ for extended periods: ${ }^{1} \mathrm{H}$ NMR $\left(500 \mathrm{MHz}, \mathrm{CDCl}_{3}\right) \delta 5.75-5.67(\mathrm{~m}, 2 \mathrm{H}), 5.42-5.32(\mathrm{~m}, 2 \mathrm{H}), 5.06(\mathrm{~d}$, $1 \mathrm{H}, J=8.9 \mathrm{~Hz}), 4.00-3.92(\mathrm{~m}, 2 \mathrm{H}), 3.03-2.95(\mathrm{~m}, 1 \mathrm{H}), 2.82-2.74(\mathrm{~m}, 2 \mathrm{H}), 1.66(\mathrm{~d}, \mathrm{~J}=1.3 \mathrm{~Hz}, 3 \mathrm{H}), 1.64$ $(\mathrm{d}, 3 \mathrm{H}, J=4.5 \mathrm{~Hz}), 1.01(\mathrm{~d}, J=6.8 \mathrm{~Hz}, 3 \mathrm{H}) \mathrm{ppm} ;{ }^{13} \mathrm{C} \mathrm{NMR}\left(125 \mathrm{MHz}, \mathrm{CDCl}_{3}\right) \delta 136.0,133.8,131.4$, 131.0, 127.2, 122.8, 35.4, 34.9, 33.3, 23.5, 21.5, 18.0 ppm; IR (film) 2964, 2927, 2868, 156, 1438, 1377 , $1203,965,854,580 \mathrm{~cm}^{-1} ;[\alpha]_{\mathrm{D}^{24}}=-69.3^{\circ}\left(c=1.00, \mathrm{CHCl}_{3}\right)$; HRMS (EI): Exact mass calcd for $\mathrm{C}_{12} \mathrm{H}_{19} \mathrm{Br}[\mathrm{M}]^{+}:$242.0670; Found: 242.0663 .

(12) Corey, E. J.; Luo, G.; Lin, L. S. J. Am. Chem. Soc. 1997, 119, 9927-9928. 


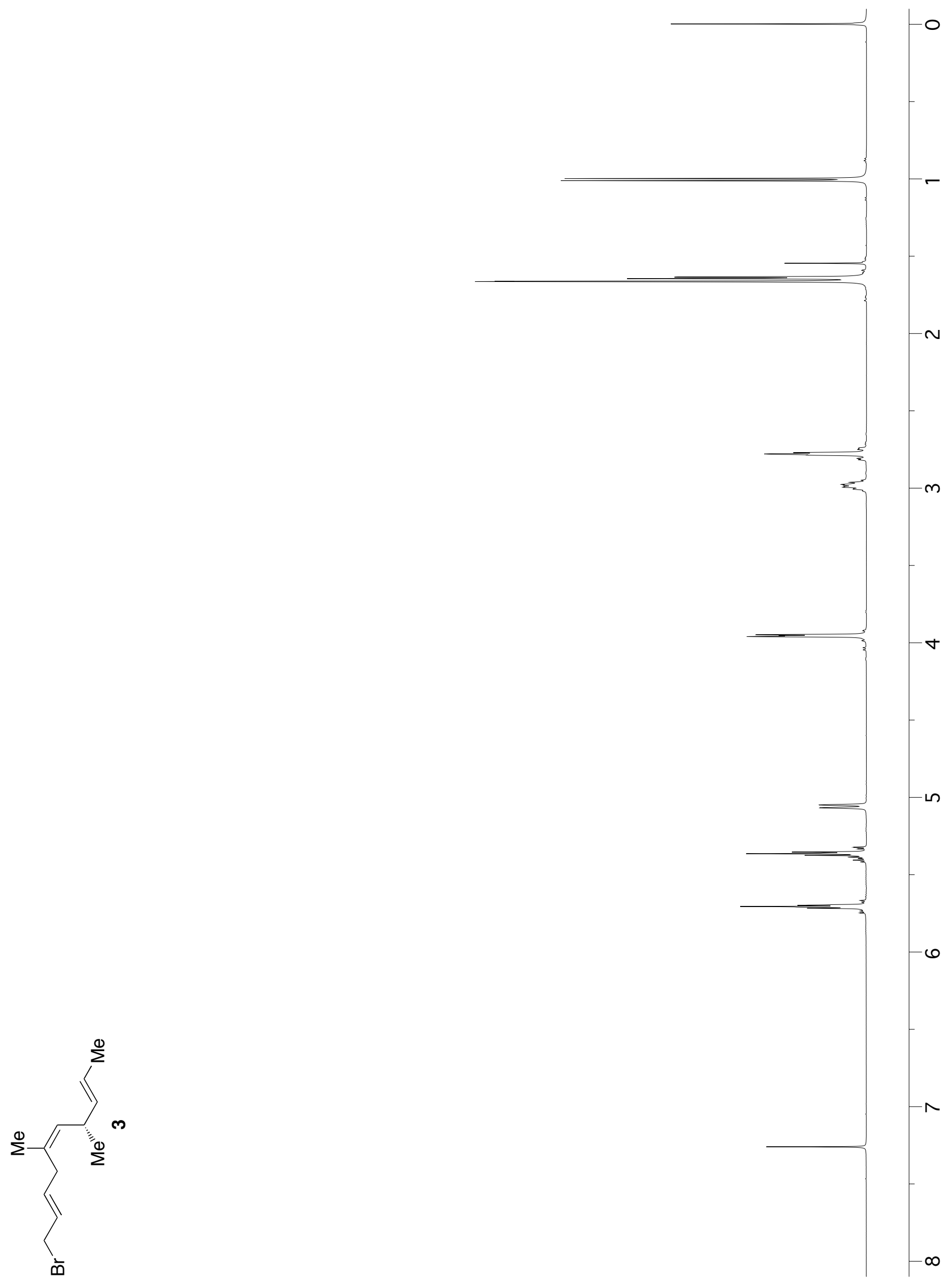

S13 


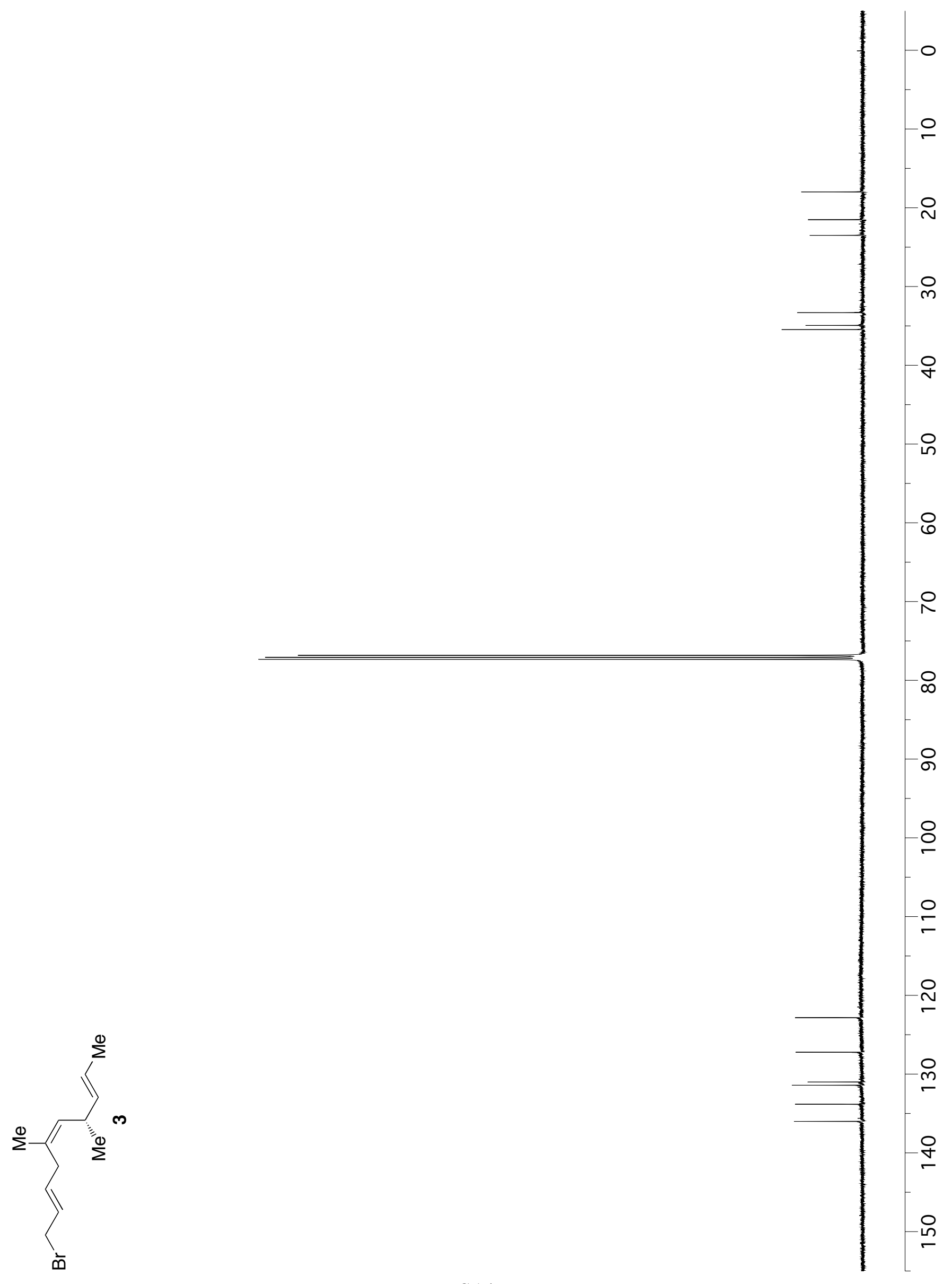


(R)-3-(2-(5-(tert-butyldimethylsilyl)-2-methyloxazol-4-yl)oxazol-4-yl)-1-((R)-4-(2-triethylsilyloxy-2propyl)-2-thioxothiazolidin-3-yl)-3-methoxypropan-1-one (8)
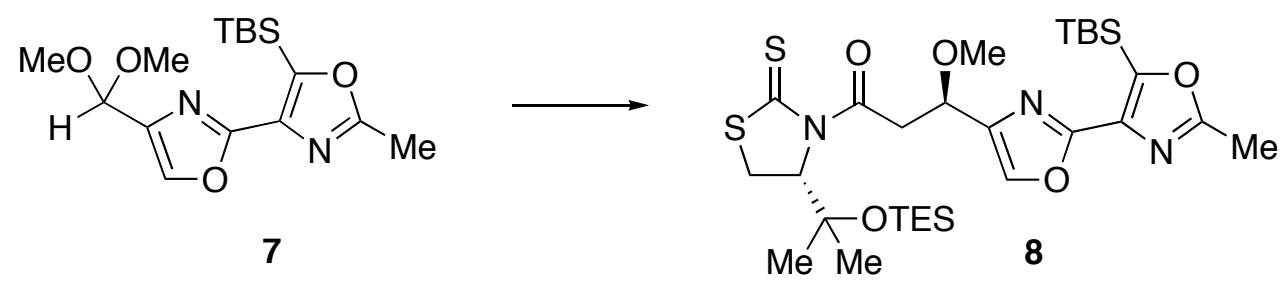

To a $100 \mathrm{~mL}$ flask was added $(R)-N$-acetyl-4-CMe $\mathrm{OTES}_{2}$-thiazolidinethione ${ }^{13}(0.1031 \mathrm{~g}, 0.309 \mathrm{mmol}, 2$ equiv) in $\mathrm{CH}_{2} \mathrm{Cl}_{2}(1.5 \mathrm{~mL})$. After flushing with $\mathrm{Ar}$, the stirring solution was cooled to $0{ }^{\circ} \mathrm{C}$ and $\mathrm{PhBCl}_{2}$ $(0.041 \mathrm{~mL}, 0.309 \mathrm{mmol}, 2$ equiv) was added dropwise via syringe. After $10 \mathrm{~min}$, sparteine $(0.142 \mathrm{~mL}$, $0.618 \mathrm{mmol}, 4$ equiv) was added via syringe. The resulting solution was warmed to rt and stirred for 30 min. The solution was cooled to $-78{ }^{\circ} \mathrm{C}$ and bisoxazole dimethyl acetal $7^{14}(0.0527 \mathrm{~g}, 0.155 \mathrm{mmol}, 1$ equiv) was added dropwise via canula in $\mathrm{CH}_{2} \mathrm{Cl}_{2}(0.5 \mathrm{~mL})$ followed by the dropwise addition of $\mathrm{BF}_{3}{ }^{\bullet} \mathrm{OEt}_{2}\left(0.030 \mathrm{~mL}, 0.232 \mathrm{mmol}, 1.5\right.$ equiv). The solution was stirred at $-78^{\circ} \mathrm{C}$ for $1.5 \mathrm{~h}$ and then was warmed to rt over $2 \mathrm{~h}$. After stirring at $\mathrm{rt}$ for $1 \mathrm{hr}$, the reaction was quenched sat aq $\mathrm{NH}_{4} \mathrm{Cl}(5 \mathrm{~mL})$. The contents of the flask were transferred to a separatory funnel containing $4: 1$ mixture of hexanes: $\mathrm{CH}_{2} \mathrm{Cl}_{2}$ $(80 \mathrm{~mL})$. The layers were separated and the aqueous layer was re-extracted with $\mathrm{CH}_{2} \mathrm{Cl}_{2}(2 \times 30 \mathrm{~mL})$ and the combined organic layers were washed with brine $(1 \times 20 \mathrm{~mL})$, dried over anhydrous $\mathrm{Na}_{2} \mathrm{SO}_{4}$, filtered, and concentrated in vacuo to give a yellow oil. ${ }^{1} \mathrm{H}$ NMR integration of the unpurified product indicated a 4:1 diastereomer ratio. This material was purified via automated silica column chromatography $\left(0.7 \rightarrow 3.5 \%\right.$ acetone $/ \mathrm{CH}_{2} \mathrm{Cl}_{2}, 110 \mathrm{~g}$ column; TLC: $\mathrm{R}_{\mathrm{f}}=0.40$ in $2 \%$ acetone $\left./ \mathrm{CH}_{2} \mathrm{Cl}_{2}\right)$ to provide diastereomerically pure methyl ether $8(0.053 \mathrm{~g}, 54 \%$ yield $)$ as a clear, yellow oil: ${ }^{1} \mathrm{H}$ NMR (500 $\left.\mathrm{MHz}, \mathrm{CDCl}_{3}\right) \delta 7.65(\mathrm{~s}, 1 \mathrm{H}), 5.28(\mathrm{~d}, J=8.2 \mathrm{~Hz} 1 \mathrm{H}), 4.84(\mathrm{dd}, J=7.5,5.1 \mathrm{~Hz}, 1 \mathrm{H}), 4.02(\mathrm{dd}, J=17.8$, $7.6 \mathrm{~Hz} 1 \mathrm{H}), 3.76(\mathrm{dd}, J=17.8,5.2 \mathrm{~Hz}, 1 \mathrm{H}), 3.46(\mathrm{dd}, J=11.3,8.1 \mathrm{~Hz}, 1 \mathrm{H}), 3.39(\mathrm{~d}, J=11.4 \mathrm{~Hz}, 1 \mathrm{H})$, $3.36(\mathrm{~s}, 3 \mathrm{H}), 2.53(\mathrm{~s}, 3 \mathrm{H}), 1.30(\mathrm{~s}, 6 \mathrm{H}), 0.95(\mathrm{t}, J=7.5 \mathrm{~Hz}, 9 \mathrm{H}), 0.95(\mathrm{~s}, 9 \mathrm{H}), 0.62(\mathrm{q}, J=7.8,6 \mathrm{H}), 0.381$ (s, 3H), 0.377 (s, 3H) ppm; ${ }^{13} \mathrm{C} \mathrm{NMR}\left(125 \mathrm{MHz}, \mathrm{CDCl}_{3}\right) \delta$ 204.8, 170.5, 165.0, 156.6, 154.9, 141.1, 139.0, 135.4, 76.7, 72.5, 72.4, 57.0, 43.4, 29.9, 28.1, 26.5, 26.1, 17.6, 13.8, 7.0, 6.6, -5.9 ppm; IR (film) $2954,2929,2876,1699,1612,1586,1464,1367,1317,1250,1154 \mathrm{~cm}^{-1} ;[\alpha]_{\mathrm{D}^{25}}=-93.3^{\circ}(c=$ 1.02, $\mathrm{CHCl}_{3}$ ); HRMS (CI): Exact mass calcd for $\mathrm{C}_{29} \mathrm{H}_{50} \mathrm{~N}_{3} \mathrm{O}_{5} \mathrm{~S}_{2} \mathrm{Si}_{2}[\mathrm{M}+\mathrm{H}]^{+}:$640.2730; Found: 640.2745 .

(13) Zhang, Y.; Sammakia, T. Org. Lett. 2004, 6, 3139-3141

(14) Smith, T. E.; Balskus, E. P. Heterocycles, 2002, 57, 1219-1225. 


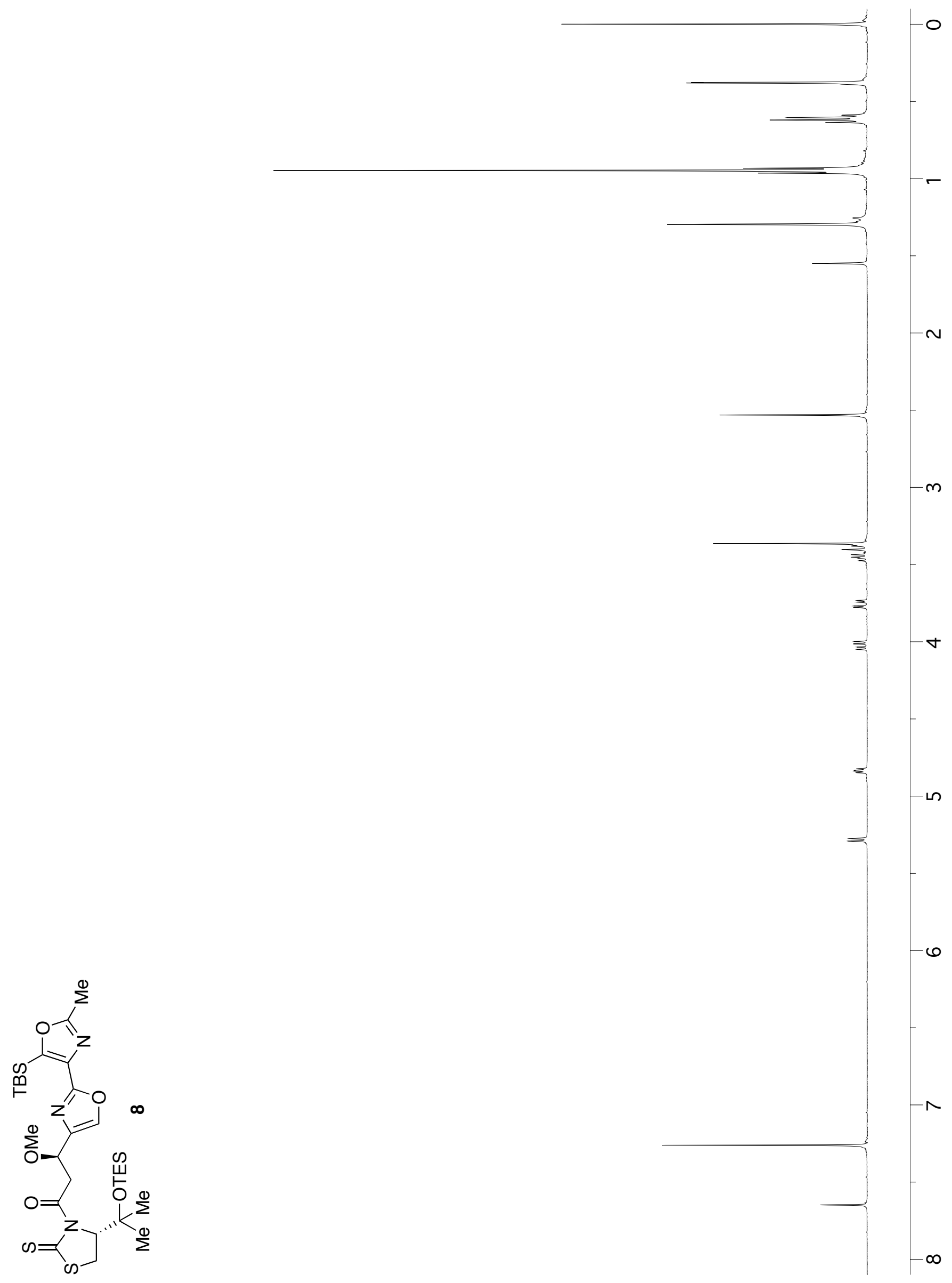




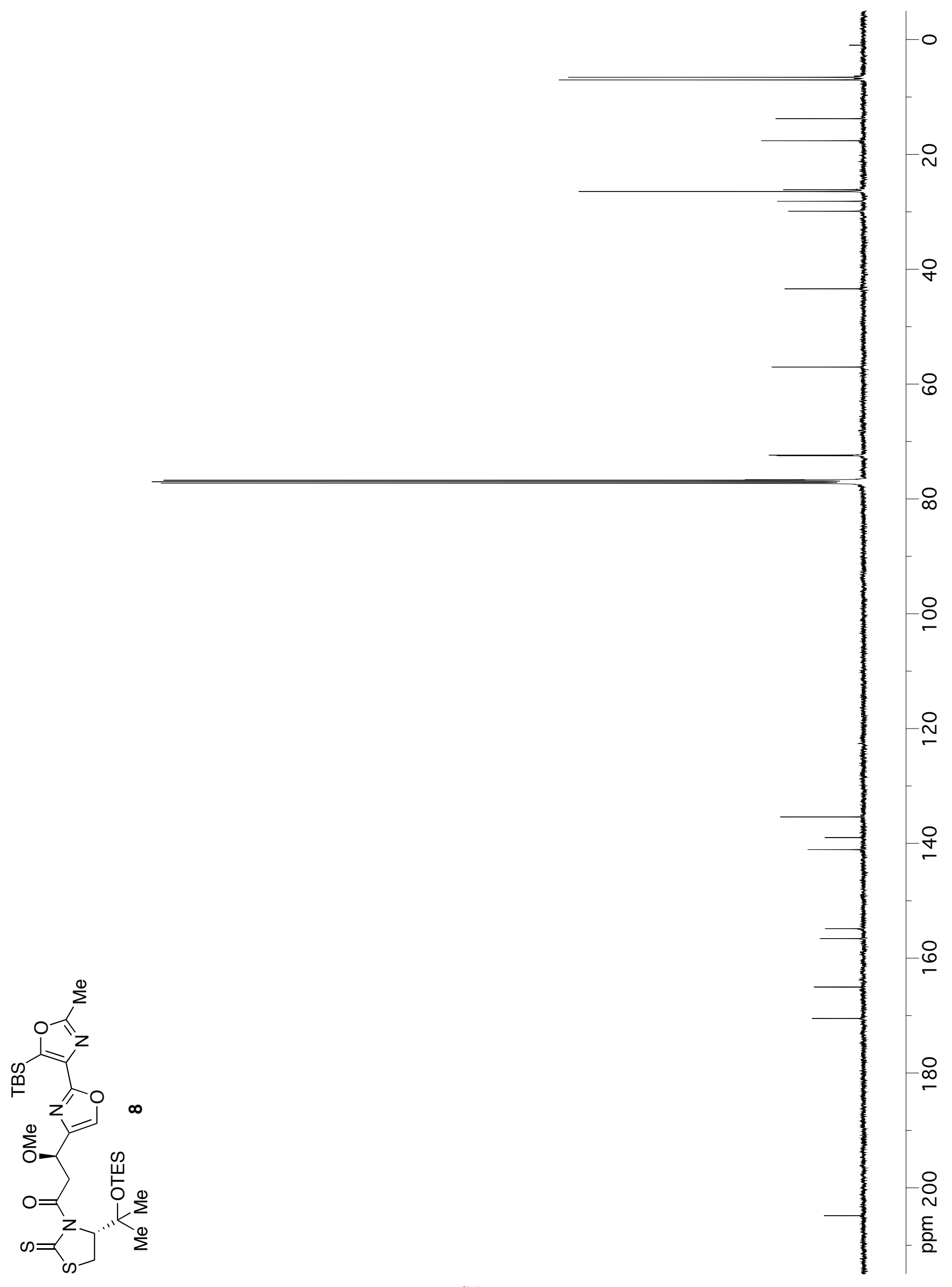


(3S,5R)-5-(2-(5-(tert-butyldimethylsilyl)-2-methyloxazol-4-yl)oxazol-4-yl)-3-hydroxy-1-((S)-4isopropyl-2-thioxothiazolidin-3-yl)-5-methoxypentan-1-one (9)

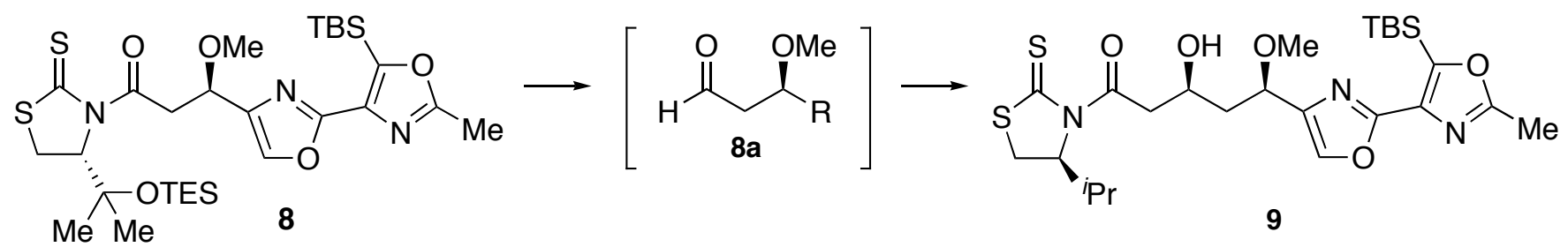

To a $10 \mathrm{~mL}$ flask containing bisoxazole methyl ether 8 ( $0.248 \mathrm{~g}, 0.388 \mathrm{mmol}, 1$ equiv) in $\mathrm{CH}_{2} \mathrm{Cl}_{2}(1.5$ $\mathrm{mL})$ under $\mathrm{N}_{2}$ at $-78{ }^{\circ} \mathrm{C}$ was added DIBAL-H $\left(0.581 \mathrm{~mL}\right.$ of a $1.0 \mathrm{M}$ solution in $\mathrm{CH}_{2} \mathrm{Cl}_{2}, 1.5$ equiv) dropwise via syringe. After stirring for $1 \mathrm{~h}$, the reaction was quenched by the addition of $\mathrm{MeOH}(7.5$ $\mathrm{mL})$. Rochelle's salt $(10 \mathrm{~mL}$ of a 7:5 mixture of saturated solution and water) was added and the biphasic mixture was warmed to $\mathrm{rt}$ and stirred rapidly for $45 \mathrm{~min}$. The layers were separated and the aqueous phase was extracted with $\mathrm{CH}_{2} \mathrm{Cl}_{2}(3 \times 25 \mathrm{~mL})$. The combined organic layers were dried over anhydrous $\mathrm{Na}_{2} \mathrm{SO}_{4}$, filtered, and concentrated in vacuo to give a colorless oil. This material was quickly subjected to flash chromatography $\left(\mathrm{CH}_{2} \mathrm{Cl}_{2}\right.$ until the auxiliary was eluted then $30 \% \mathrm{Et}_{2} \mathrm{O} / \mathrm{CH}_{2} \mathrm{Cl}_{2}$; TLC: $\mathrm{R}_{\mathrm{f}}=0.09$ in $70 \% \mathrm{Et}_{2} \mathrm{O} /$ hexanes $)$ to provide $(R)$-3-(2-(5-(tert-butyldimethylsilyl)-2-methyloxazol-4yl)oxazol-4-yl)-3-methoxypropanal (8a) as a relatively unstable clear oil that was used immediately in the next step: ${ }^{1} \mathrm{H}$ NMR $\left(500 \mathrm{MHz}, \mathrm{CDCl}_{3}\right) \delta 9.83(\mathrm{~s}, 1 \mathrm{H}), 7.67(\mathrm{~s}, 1 \mathrm{H}), 4.81(\mathrm{~d}, J=7.6,4.7 \mathrm{~Hz}, 1 \mathrm{H})$, $3.38(\mathrm{~s}, 3 \mathrm{H}), 3.03$ (dd, $J=16.9,7.7 \mathrm{~Hz}, 1 \mathrm{H}), 2.94(\mathrm{dd}, J=16.9,4.6 \mathrm{~Hz}, 1 \mathrm{H}), 2.55(\mathrm{~s}, 3 \mathrm{H}), 0.96(\mathrm{~s}, 9 \mathrm{H})$, 0.34 (s, 6H) ppm; ${ }^{13} \mathrm{C} \mathrm{NMR}\left(125 \mathrm{MHz}, \mathrm{CDCl}_{3}\right) \delta$ 200.0, 165.1, 156.8, 154.8, 140.8, 138.7, 135.2, 71.3, $56.9,48.0,26.3,17.4,13.6,-6.0 \mathrm{ppm}$.

To a $10 \mathrm{~mL}$ flask was added $\mathrm{Sn}(\mathrm{OTf})_{2}(0.353 \mathrm{~g}, 0.847 \mathrm{mmol}, 2.3$ equiv) in a glove box. This tin compound was dissolved in $\mathrm{CH}_{2} \mathrm{Cl}_{2}(3.5 \mathrm{~mL})$, the flask was cooled to $-50{ }^{\circ} \mathrm{C}, \mathrm{N}$-ethyl piperidine $(0.121$ $\mathrm{mL}, 0.884 \mathrm{mmol}, 2.4$ equiv) was added dropwise via syringe, followed by $(S)$ - $N$-acetyl-4-i $\mathrm{Pr}$ thazolidinethione $\left(0.122 \mathrm{~g}, 0.552 \mathrm{mmol}, 1.5\right.$ equiv). The solution was stirred at $-50{ }^{\circ} \mathrm{C}$ for $4.5 \mathrm{~h}$ to form the tin enolate and then was cooled to $-110{ }^{\circ} \mathrm{C}$ in a liquid nitrogen/hexanes slurry before aldehyde 8a (theoretical from above, $0.388 \mathrm{mmol}, 1$ equiv) was added via canula in $\mathrm{CH}_{2} \mathrm{Cl}_{2}(1.5 \mathrm{~mL})$. The solution was kept between -90 and $-100{ }^{\circ} \mathrm{C}$ for $2 \mathrm{~h}$ and was then warmed to $-78{ }^{\circ} \mathrm{C}$ over $30 \mathrm{~min}$ and allowed to stir for an additional $30 \mathrm{~min}$ at $-78^{\circ} \mathrm{C}$. The reaction was quenched with $\mathrm{pH} 7$ buffer and filtered with $\mathrm{CH}_{2} \mathrm{Cl}_{2}(25 \mathrm{~mL})$ through a plug of Celite into a separatory funnel containing sat. aq. $\mathrm{NaHCO}_{3}(15 \mathrm{~mL})$. The layers were separated and the aqueous layer was extracted with $\mathrm{CH}_{2} \mathrm{Cl}_{2}(2 \times 30 \mathrm{~mL})$. The combined organic phases were dried over anhydrous $\mathrm{Na}_{2} \mathrm{SO}_{4}$, filtered, and concentrated in vacuo to give a clear yellow oil. ${ }^{1} \mathrm{HNMR}$ integration of the unpurified product indicated a 3:1 diastereomer ratio. This material was purified via automated silica column chromatography $(40 \rightarrow 70 \%$ EtOAc/hexanes, $110 \mathrm{~g}$ column; TLC: $\mathrm{R}_{\mathrm{f}}=0.28$ in $70 \%$ EtOAc/hexanes) to provide diastereomerically pure alcohol $9(0.2142 \mathrm{~g}$, $46 \%$ yield over two steps) as a clear, yellow oil: ${ }^{1} \mathrm{H}$ NMR $\left(500 \mathrm{MHz}, \mathrm{CDCl}_{3}\right) \delta 7.65(\mathrm{~s}, 1 \mathrm{H}), 5.15(\mathrm{dd}, J$ $=7.0,6.8 \mathrm{~Hz}, 1 \mathrm{H}), 4.53(\mathrm{dd}, J=7.2,6.3 \mathrm{~Hz}, 1 \mathrm{H}), 4.33-4.26(\mathrm{~m}, 1 \mathrm{H}), 3.57-3.47(\mathrm{~m}, 3 \mathrm{H}), 3.39-3.30(\mathrm{~m}$, $1 \mathrm{H}), 3.34(\mathrm{~s}, 3 \mathrm{H}), 3.03(\mathrm{~d}, J=11.1 \mathrm{~Hz}, 1 \mathrm{H}), 2.54(\mathrm{~s}, 3 \mathrm{H}), 2.42-2.31(\mathrm{~m}, 1 \mathrm{H}), 2.20-2.12(\mathrm{~m}, 1 \mathrm{H}), 2.11$ $-2.03(\mathrm{~m}, 1 \mathrm{H}) .1 .06(\mathrm{~d}, J=6.7 \mathrm{~Hz}, 3 \mathrm{H}), 0.97(\mathrm{~d}, J=7.3 \mathrm{~Hz}, 3 \mathrm{H}), 0.95(\mathrm{~s}, 9 \mathrm{H}), 0.38(\mathrm{~s}, 6 \mathrm{H}) \mathrm{ppm} ;{ }^{13} \mathrm{C}$ NMR $\left(125 \mathrm{MHz}, \mathrm{CDCl}_{3}\right) \delta 202.8,172.2,165.0,156.7,154.7,141.3,138.9,135.3,75.1,71.3,66.4,56.6$, 45.4, 40.9, 30.7, 30.5, 26.5, 19.0, 17.7, 17.5, 13.7, -5.9 ppm; IR (film) 3420, 2958, 2930, 2855, 1696, $1616,1583,1469,1363,1314,1157,1094,1036,930,844,781,730,668 \mathrm{~cm}^{-1} ;[\alpha]_{\mathrm{D}}^{25}=+212.1^{\circ}(c=$ 1.03, $\mathrm{CHCl}_{3}$ ); HRMS (CI): Exact mass calcd for $\mathrm{C}_{25} \mathrm{H}_{40} \mathrm{~N}_{3} \mathrm{O}_{5} \mathrm{~S}_{2} \mathrm{Si}[\mathrm{M}+\mathrm{H}]^{+}$: 554.2179; Found: 554.2181. 


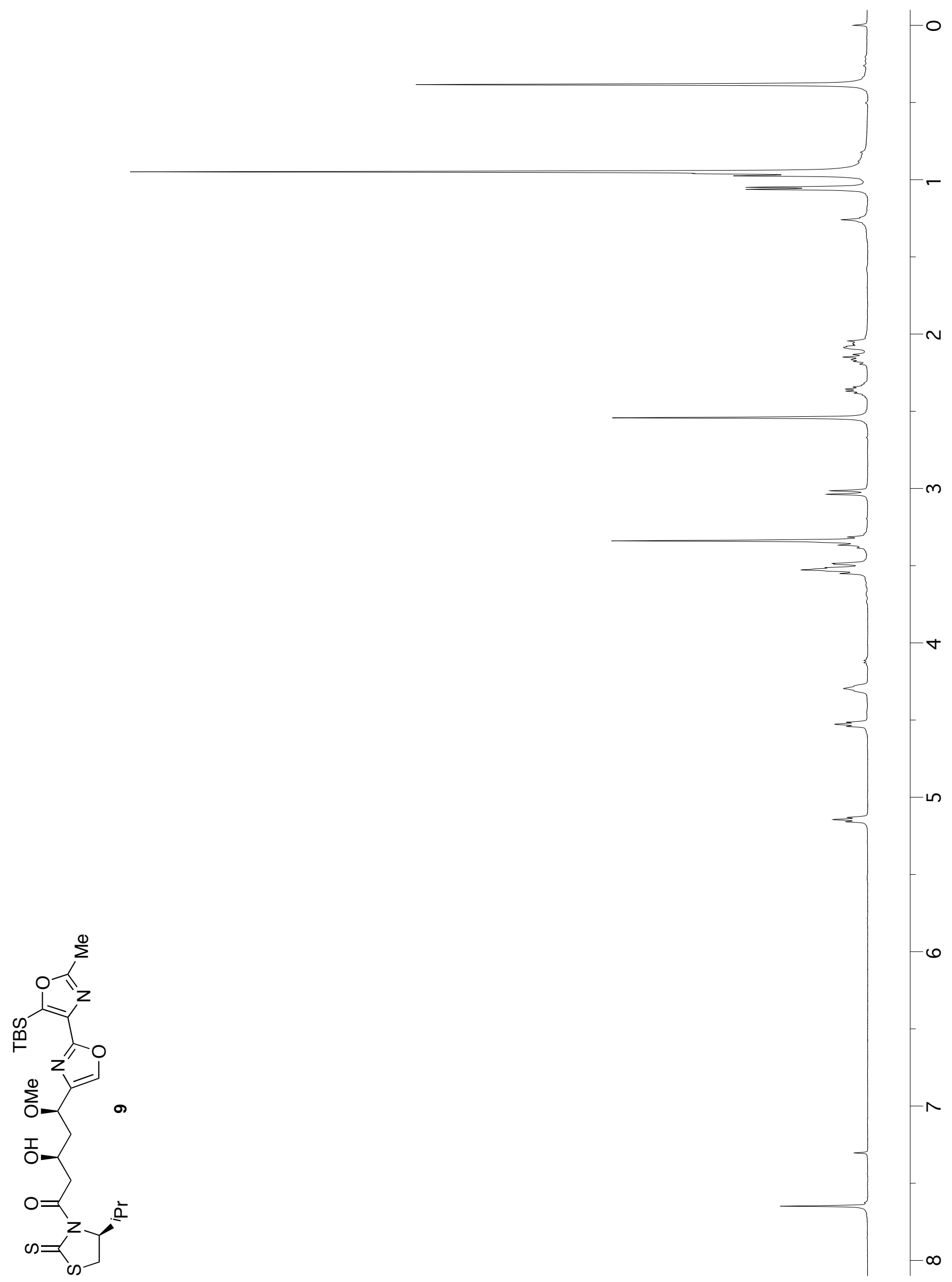




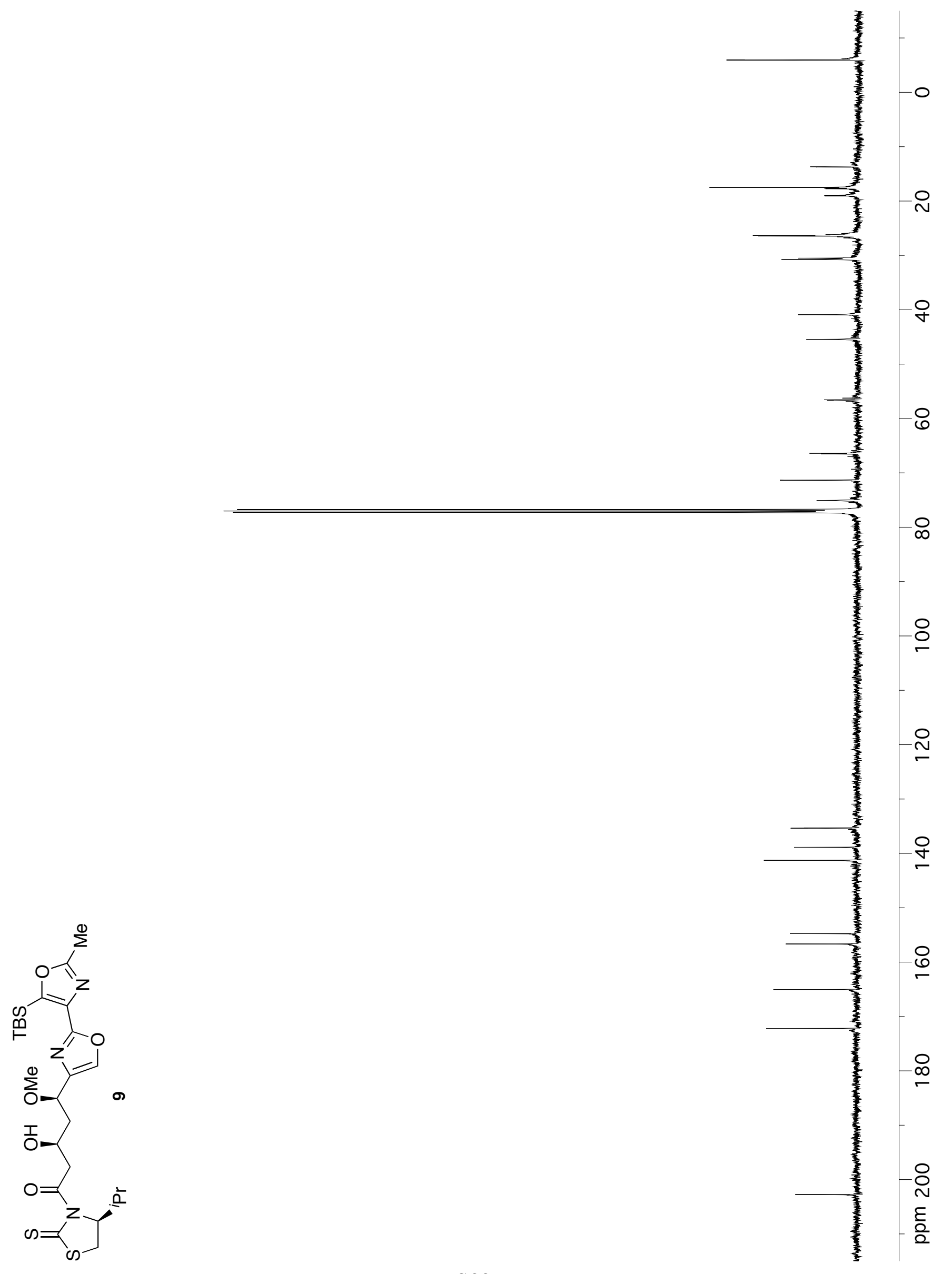


(S)-2-((R)-2-(2-(5-(tert-butyldimethylsilyl)-2-methyloxazol-4-yl)oxazol-4-yl)-2-methoxyethyl)-2,3dihydro-6-methylpyran-4-one (10)

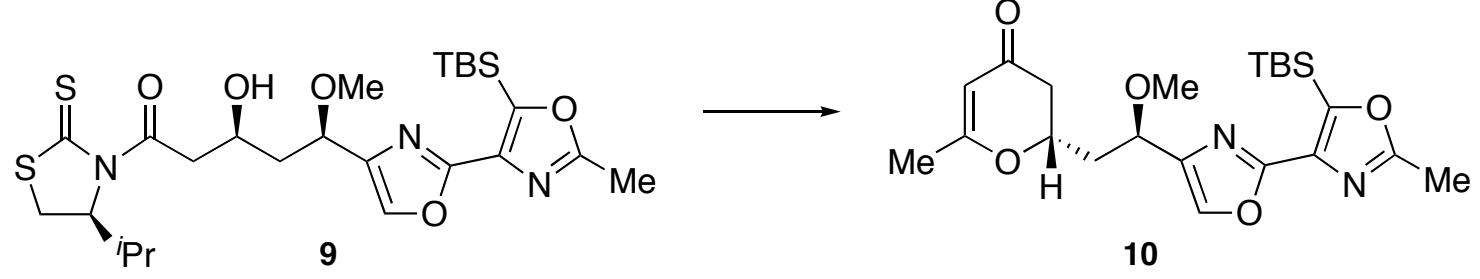

To a $10 \mathrm{~mL}$ flask containing alcohol 9 (0.2380 g, $0.431 \mathrm{mmol}, 1$ equiv) in DMF (2.7 mL) under an Ar atmosphere was added magnesium acetoacetate ${ }^{15}(0.195 \mathrm{mg}, 0.861 \mathrm{mmol}, 2$ equiv) and imidazole (32.2 $\mathrm{mg}, 0.474 \mathrm{mmol}, 1.1$ equiv). After stirring for $29 \mathrm{~h}$, the mixture was cooled to $0{ }^{\circ} \mathrm{C}$ in an ice bath, diluted with THF (3 mL), quenched with $7.5 \mathrm{~mL}$ of $2 \mathrm{M} \mathrm{HCl}$, and stirred overnight. The layers were separated and the aqueous layer was extracted with EtOAc $(4 \times 20 \mathrm{~mL})$. The combined organic phases were dried over anhydrous $\mathrm{Na}_{2} \mathrm{SO}_{4}$, filtered, and concentrated in vacuo. This material was purified via automated silica column chromatography $\left(55 \rightarrow 80 \%\right.$ EtOAc/hexanes, $110 \mathrm{~g}$ column; TLC: $\mathrm{R}_{\mathrm{f}}=0.40$ in $80 \% \mathrm{EtOAc} / \mathrm{hexanes})$ to provide dihydropyranone $10(0.1215 \mathrm{~g}, 65 \%$ yield $)$ as a clear colorless oil: ${ }^{1} \mathrm{H}$ NMR (500 MHz, $\left.\mathrm{CDCl}_{3}\right) \delta 7.65(\mathrm{~s}, 1 \mathrm{H}), 5.30(\mathrm{~s}, 1 \mathrm{H}), 4.51-4.43(\mathrm{~m}, 2 \mathrm{H}), 3.33(\mathrm{~s}, 3 \mathrm{H}), 2.55(\mathrm{~s}, 3 \mathrm{H})$, 2.58-2.40 (m, 3H), 2.25 (ddd, $J=13.5,6.0,6.0 \mathrm{~Hz}, 1 \mathrm{H}), 1.97$ (s, 3H), 0.95 (s, 9H), 0.38 (s, 6H) ppm; ${ }^{13} \mathrm{C} \mathrm{NMR}\left(125 \mathrm{MHz}, \mathrm{CDCl}_{3}\right) \delta$ 192.4, 174.0, 165.1, 156.8, 154.8, 141.1, 138.8, 135.4, 104.8, 76.2, 72.6, 56.6, 40.6, 39.1, 26.3, 20.9, 17.5, 13.7, -6.00 ppm; IR (film) 2954, 2929, 2859, 1670, 1612, 1465, 1399, 1334, 1249, 1109, 1033, 842, 824, 781, $680 \mathrm{~cm}^{-1} ;[\alpha]_{\mathrm{D}^{25}}=-36.7^{\circ}\left(c=0.96, \mathrm{CHCl}_{3}\right)$; HRMS (CI): Exact mass calcd for $\mathrm{C}_{22} \mathrm{H}_{33} \mathrm{~N}_{2} \mathrm{O}_{5} \mathrm{Si}[\mathrm{M}+\mathrm{H}]^{+}$: 433.2159; Found: 433.2171.

(15) Ohta, S.; Tsujimura, A.; Okamoto, M. Chem. Pharm Bull. 1989, 21, 2762-2768. 


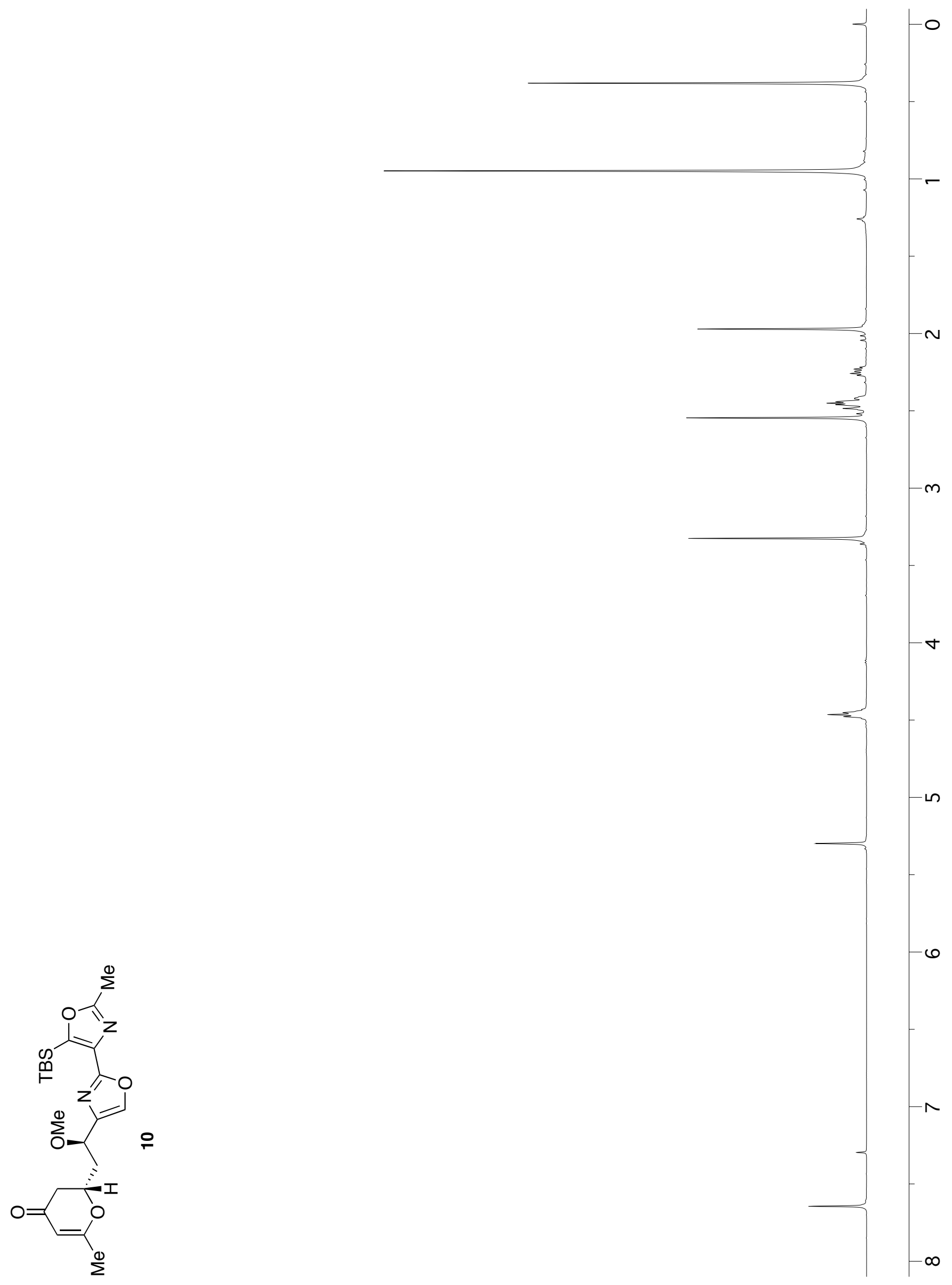




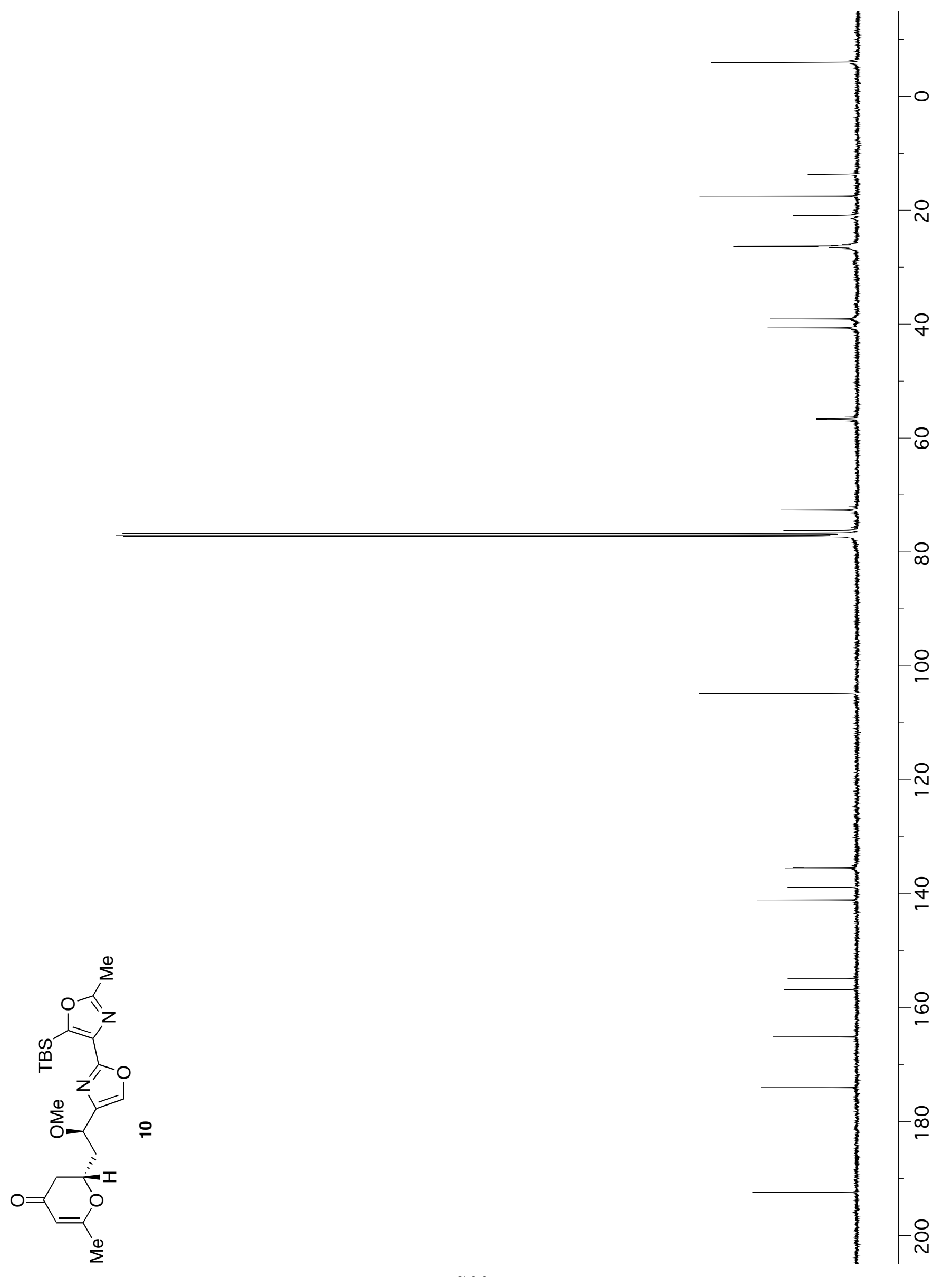




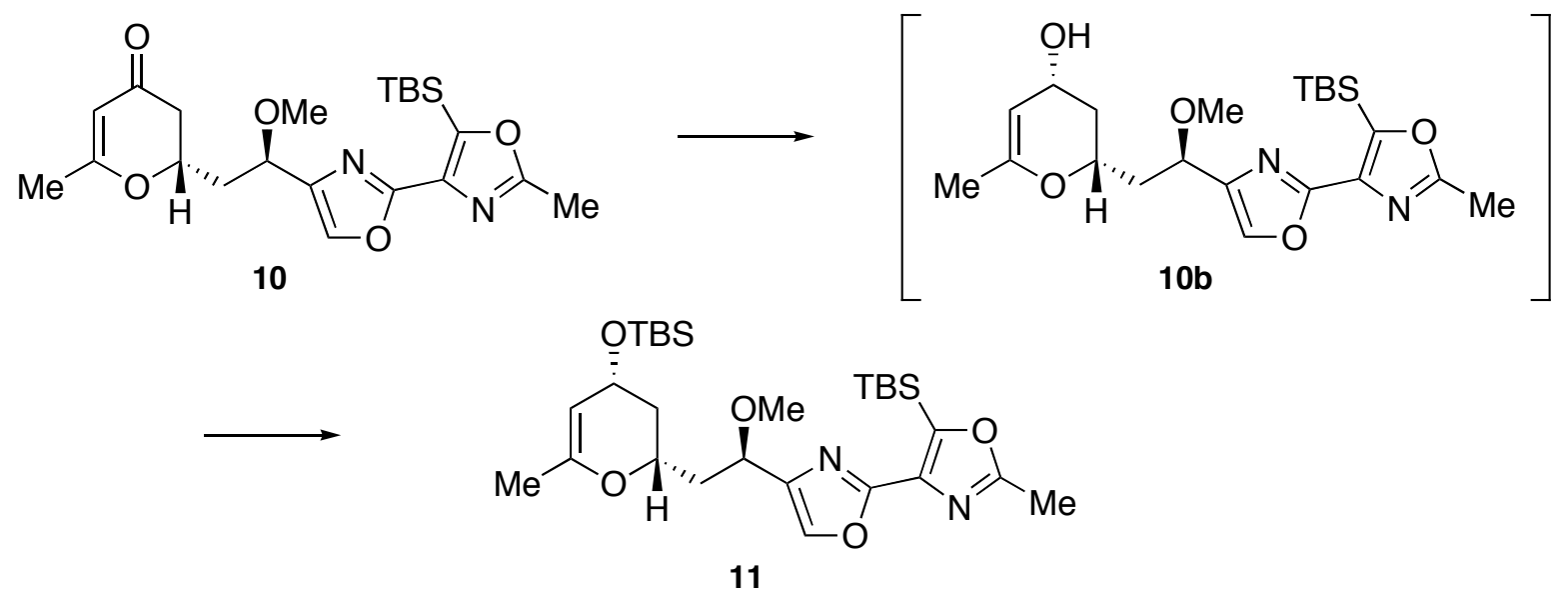

To a $10 \mathrm{~mL}$ flask containing dihydropyranone $10(23.3 \mathrm{mg}, 0.0539 \mathrm{mmol}, 1$ equiv) under an $\mathrm{Ar}$ atmosphere was added a solution of $\mathrm{CeCl}_{3} \cdot 7 \mathrm{H}_{2} \mathrm{O}(22.1 \mathrm{mg}, 0.0593 \mathrm{mmol}, 1.1$ equiv) in a 1:1 mixture of $\mathrm{THF} / \mathrm{MeOH}(0.77 \mathrm{~mL})$. The suspension was cooled to $-78{ }^{\circ} \mathrm{C}$ and $\mathrm{NaBH}_{4}(4.2 \mathrm{mg}, 0.108 \mathrm{mmol}, 2$ equiv) was added as a solid in one portion. After $15 \mathrm{~min}$, the flask was warmed to $-50{ }^{\circ} \mathrm{C}$ and then allowed to warm to $-30^{\circ} \mathrm{C}$ over $1 \mathrm{~h}$. The reaction mixture was poured into $\mathrm{pH} 7$ buffer $(15 \mathrm{~mL})$ and was diluted with $\mathrm{Et}_{2} \mathrm{O}(5 \mathrm{~mL})$. The layers were separated and the aqueous phase was extracted with EtOAc $(3 \times 25 \mathrm{~mL})$ The combined organic layers were filtered through a plug of silica gel and concentrated in vacuo to give $(2 R, 4 R)-2-((R)-2-(2-(5-$ (tert-butyldimethylsilyl)-2-methyloxazol-4-yl)oxazol-4-yl)-2methoxyethyl)-3,4-dihydro-6-methyl-2H-pyran-4-ol, tert-butyldimethylsilyl ether (10b) which was carried on immediately without any further purification: TLC: $\mathrm{R}_{\mathrm{f}}=0.36$ in $80 \%$ EtOAc/hexanes.

To a $5 \mathrm{~mL}$ flask containing allylic alcohol $\mathbf{1 0 b}$ (theoretical from above, $0.0593 \mathrm{mmol}, 1$ equiv) under an Ar atmosphere was added imidazole $(10.8 \mathrm{mg}, 0.162 \mathrm{mmol}, 3$ equiv) a catalytic amount of DMAP, and anhydrous DMF ( $0.5 \mathrm{~mL})$. TBS-Cl (17.6 mg, $0.116 \mathrm{mmol}, 2.2$ equiv) was added and the reaction was stirred for $4 \mathrm{~h}$. The solution was diluted with brine $(5 \mathrm{~mL})$ and EtOAc $(5 \mathrm{~mL})$, the layers were separated, and the aqueous layer was extracted with EtOAc $(3 \times 10 \mathrm{~mL})$. The combined organics were washed with water $(2 \times 8 \mathrm{~mL})$, dried over anhydrous $\mathrm{Na}_{2} \mathrm{SO}_{4}$, filtered, and concentrated in vacuo. This material was purified via flash chromatography (45\% EtOAc/hexanes, TLC: $\mathrm{R}_{\mathrm{f}}=0.31$ in $10 \% \mathrm{Et}_{2} \mathrm{O} / \mathrm{CH}_{2} \mathrm{Cl}_{2}$ ) to provide TBS ether $\mathbf{1 1}\left(18.6 \mathrm{mg}, 70 \%\right.$ yield over two steps) as a clear colorless oil: ${ }^{1} \mathrm{H}$ NMR $(500 \mathrm{MHz}$, $\left.\mathrm{CDCl}_{3}\right) \delta 7.63(\mathrm{~s}, 1 \mathrm{H}), 4.46(\mathrm{dd}, J=8.0,6.0 \mathrm{~Hz}, 1 \mathrm{H}), 4.42(\mathrm{~s}, 1 \mathrm{H}), 4.35(\mathrm{dd}, J=8.3,7.0 \mathrm{~Hz}, 1 \mathrm{H}), 3.86$ $-3.78(\mathrm{~m}, 1 \mathrm{H}), 3.29(\mathrm{~s}, 3 \mathrm{H}), 2.54(\mathrm{~s}, 3 \mathrm{H}), 2.26(\mathrm{ddd}, J=14.3,8.7,5.9 \mathrm{~Hz}, 1 \mathrm{H}), 2.15$ (ddd, $J=12.7,8.2$, $4.3 \mathrm{~Hz}, 1 \mathrm{H}), 1.95(\mathrm{dd}, J=13.0,6.6 \mathrm{~Hz}, 1 \mathrm{H}), 1.69(\mathrm{~s}, 3 \mathrm{H}), 1.68-1.59(\mathrm{~m}, 1 \mathrm{H}), 0.95(\mathrm{~s}, 9 \mathrm{H}), 0.88(\mathrm{~s}, 9 \mathrm{H})$, 0.39 (s, 3H), 0.38 (s, 3H), 0.06 (s, 6H) ppm; ${ }^{13} \mathrm{C}$ NMR (125 MHz, $\left.\mathrm{CDCl}_{3}\right) \delta$ 165.1, 156.6, 154.7, 152.0, 141.2, 139.1, 135.9, 101.3, 72.6, 71.5, 64.3, 56.3, 39.5, 37.6, 26.5, 25.9, 19.8, 18.2, 17.6, 13.8, -4.7, -5.9 ppm; IR (film) 2928, 2857, 1675, 1586, 1463, 1383, 1252, 1062, 837, 837, 780, $495 \mathrm{~cm}^{-1} ;[\alpha]_{\mathrm{D}^{25}}=$ $+18.5^{\circ}\left(c=1.00, \mathrm{CHCl}_{3}\right)$; HRMS (CI): Exact mass calcd for $\mathrm{C}_{28} \mathrm{H}_{48} \mathrm{~N}_{2} \mathrm{O}_{5} \mathrm{Si} 2 \mathrm{Li}[\mathrm{M}+\mathrm{Li}]^{+}: 555.3262$; Found: 555.3267. 


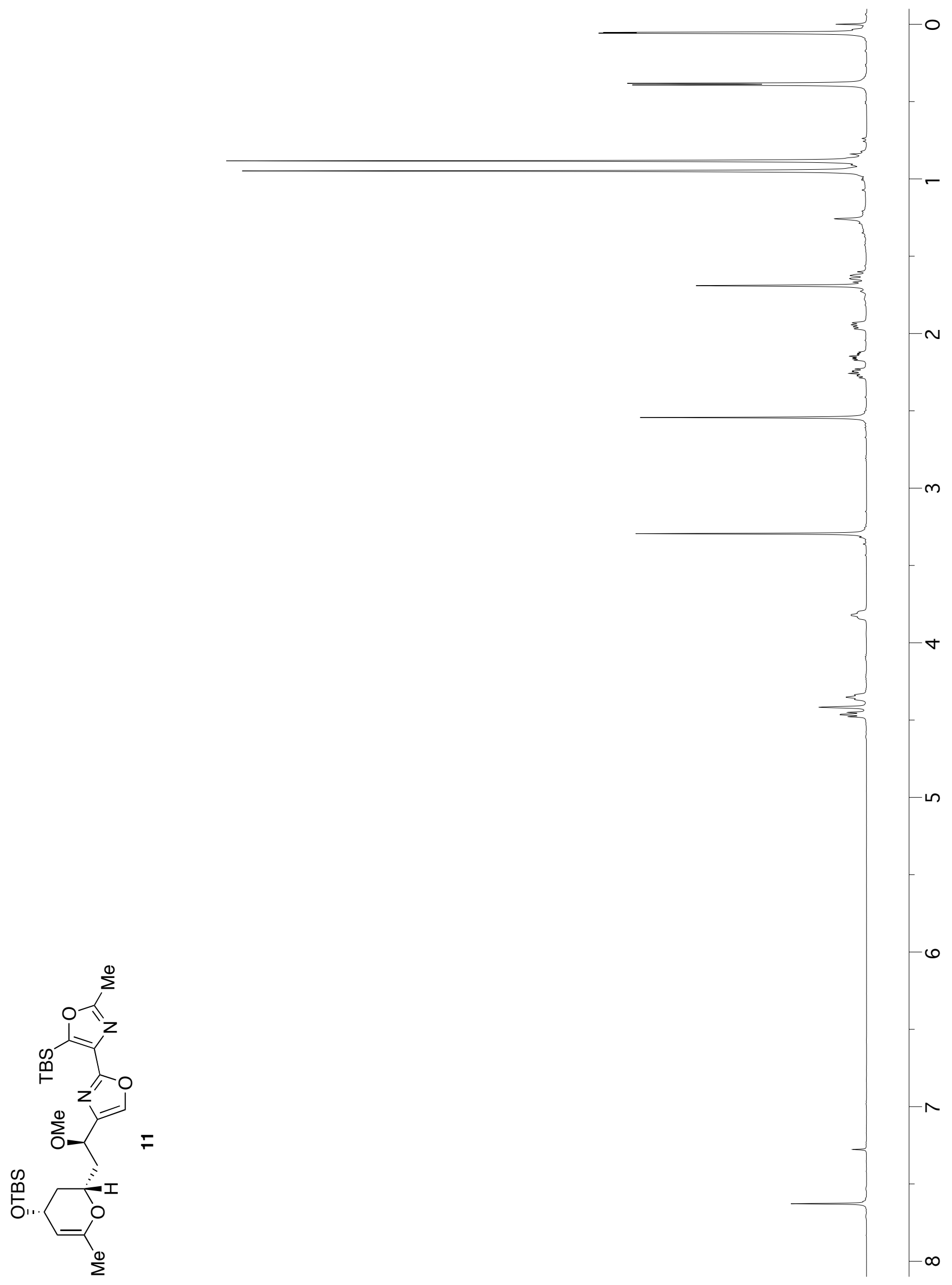




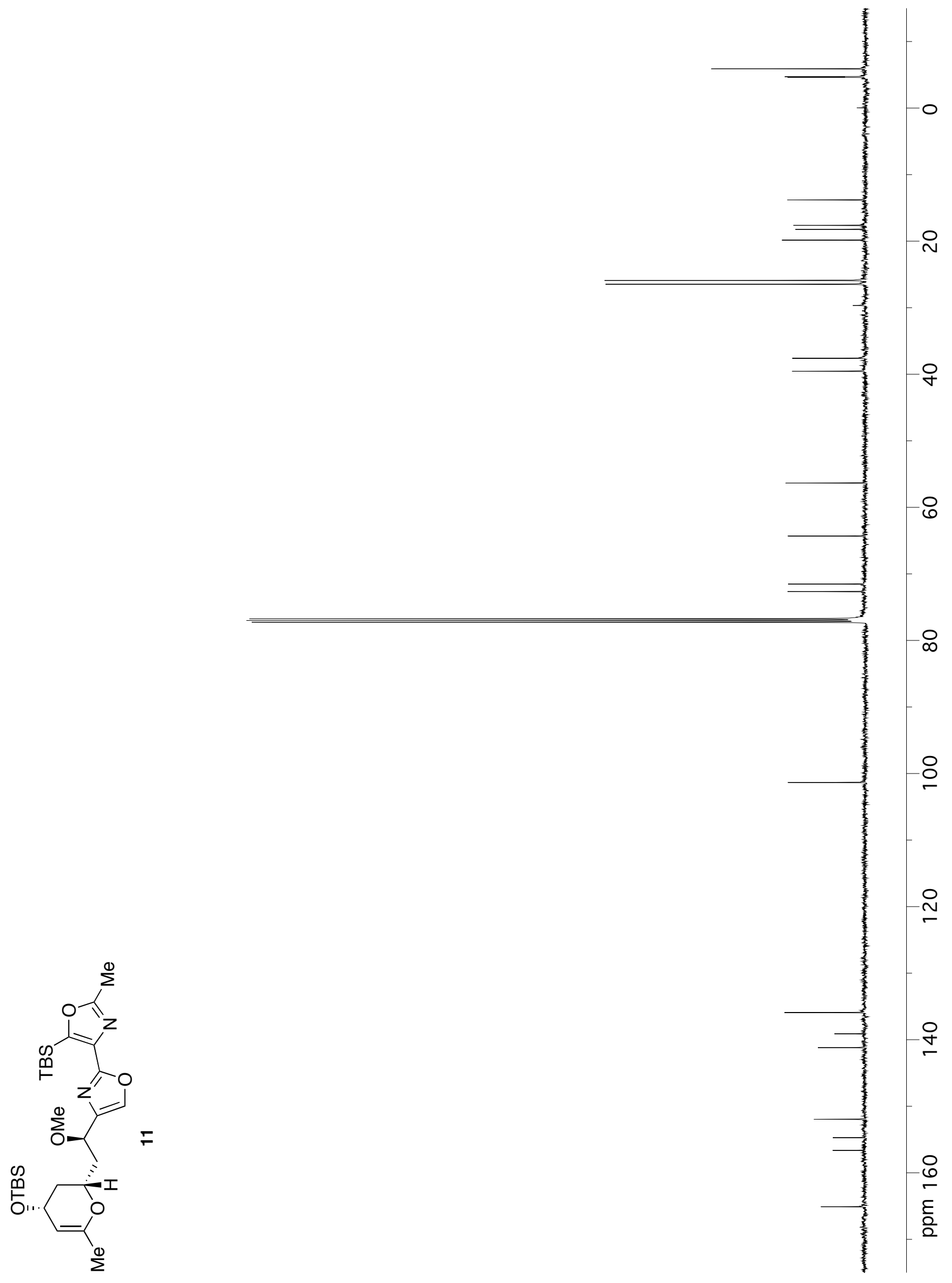




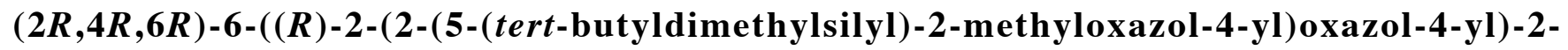
methoxyethyl)-tetrahydro-2-methoxy-2-methyl-2H-pyran-4-ol, tert-butyldimethylsilyl ether (2)<smiles>CO[C@H](C[C@@H]1C[C@@H](O[SbH3])C=C(C)O1)c1coc(-c2nc(C)oc2SC(C)(C)C)n1</smiles>

11

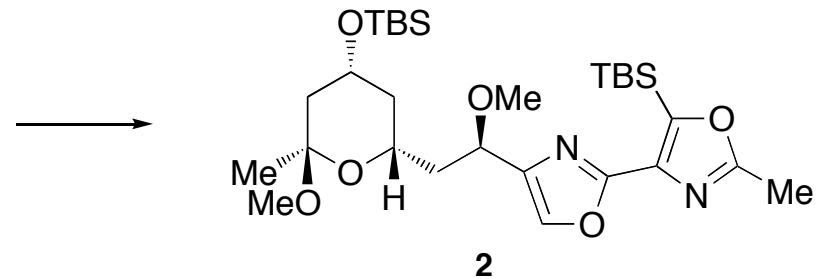

2

To a $5 \mathrm{~mL}$ flask containing TBS ether 11 ( $4.8 \mathrm{mg}, 0.0087 \mathrm{mmol}, 1$ equiv) in benzene $(0.3 \mathrm{~mL})$ under an Ar atmosphere was added $\mathrm{MeOH}$ ( $11 \mu \mathrm{L}, 30$ equiv) and trimethyl orthoformate (5 $\mu \mathrm{L}, 5$ equiv). A spatula tip of PPTS was added in one portion and the reaction was stirred for $75 \mathrm{~min}$. The reaction was quenched with sat. aq. $\mathrm{NaHCO}_{3}(3 \mathrm{~mL})$ and diluted with EtOAc $(5 \mathrm{~mL})$. The layers were separated and the aqueous phase was further extracted with EtOAc $(2 \times 10 \mathrm{~mL})$. The combined organics were dried over anhydrous $\mathrm{Na}_{2} \mathrm{SO}_{4}$, filtered, and concentrated in vacuo. This material was purified via flash chromatography (35\% EtOAc/hexanes, TLC: $\mathrm{R}_{\mathrm{f}}=0.57$ in $40 \%$ EtOAc/hexanes) to provide mixed methyl acetal $2\left(5.1 \mathrm{mg}, 88 \%\right.$ yield) as a clear colorless oil: ${ }^{1} \mathrm{H} \mathrm{NMR}\left(500 \mathrm{MHz}, \mathrm{CDCl}_{3}\right) \delta 7.62(\mathrm{~s}, 1 \mathrm{H})$, $4.45(\mathrm{dd}, J=7.7,6.4 \mathrm{~Hz}, 1 \mathrm{H}), 4.02-3.93(\mathrm{~m}, 1 \mathrm{H}), 3.51-3.42(\mathrm{~m}, 1 \mathrm{H}), 3.29(\mathrm{~s}, 3 \mathrm{H}), 3.00(\mathrm{~s}, 3 \mathrm{H}), 2.54(\mathrm{~s}$, $3 \mathrm{H}), 2.18-2.06(\mathrm{~m}, 2 \mathrm{H}), 1.95(\mathrm{dd}, J=12.8,4.5 \mathrm{~Hz} 1 \mathrm{H}), 1.79(\mathrm{~d}, J=10.3 \mathrm{~Hz}, 1 \mathrm{H}), 1.31(\mathrm{dd}, J=23.7$, $11.6 \mathrm{~Hz}, 1 \mathrm{H}), 1.30$ (s, 3H), 1.22 (dd, $J=23.6,11.8 \mathrm{~Hz}, 1 \mathrm{H}), 0.95$ (s, 9H), 0.87 (s, 9H), 0.39 (s, 3H), 0.38 (s, 3H), 0.04 (s, 6H) ppm; ${ }^{13} \mathrm{C}$ NMR $\left(125 \mathrm{MHz}, \mathrm{CDCl}_{3}\right) \delta$ 165.1, 156.6, 154.8, 141.4, 139.1, 135.9, 99.6, $72.7,65.8,65.1,56.3,47.6,45.3,41.0,40.3,26.5,25.8,23.7,18.0,17.6,13.8,-4.6,-5.9$ ppm; IR (film) 2929, 2857, 1612, 1586, 1463, 1377, 1319, 1251, 1192, 1084, 1034, 930, 914, 870, 837, 779, 670, $580,490 \mathrm{~cm}^{-1} ;[\alpha]_{D^{25}}=-20.1^{\circ}\left(c=1.01, \mathrm{CHCl}_{3}\right)$; HRMS (CI): Exact mass calcd for $\mathrm{C}_{29} \mathrm{H}_{52} \mathrm{~N}_{2} \mathrm{O}_{6} \mathrm{Si}_{2} \mathrm{Li}$ $[\mathrm{M}+\mathrm{Li}]^{+}:$587.3479; Found: 587.3523. 


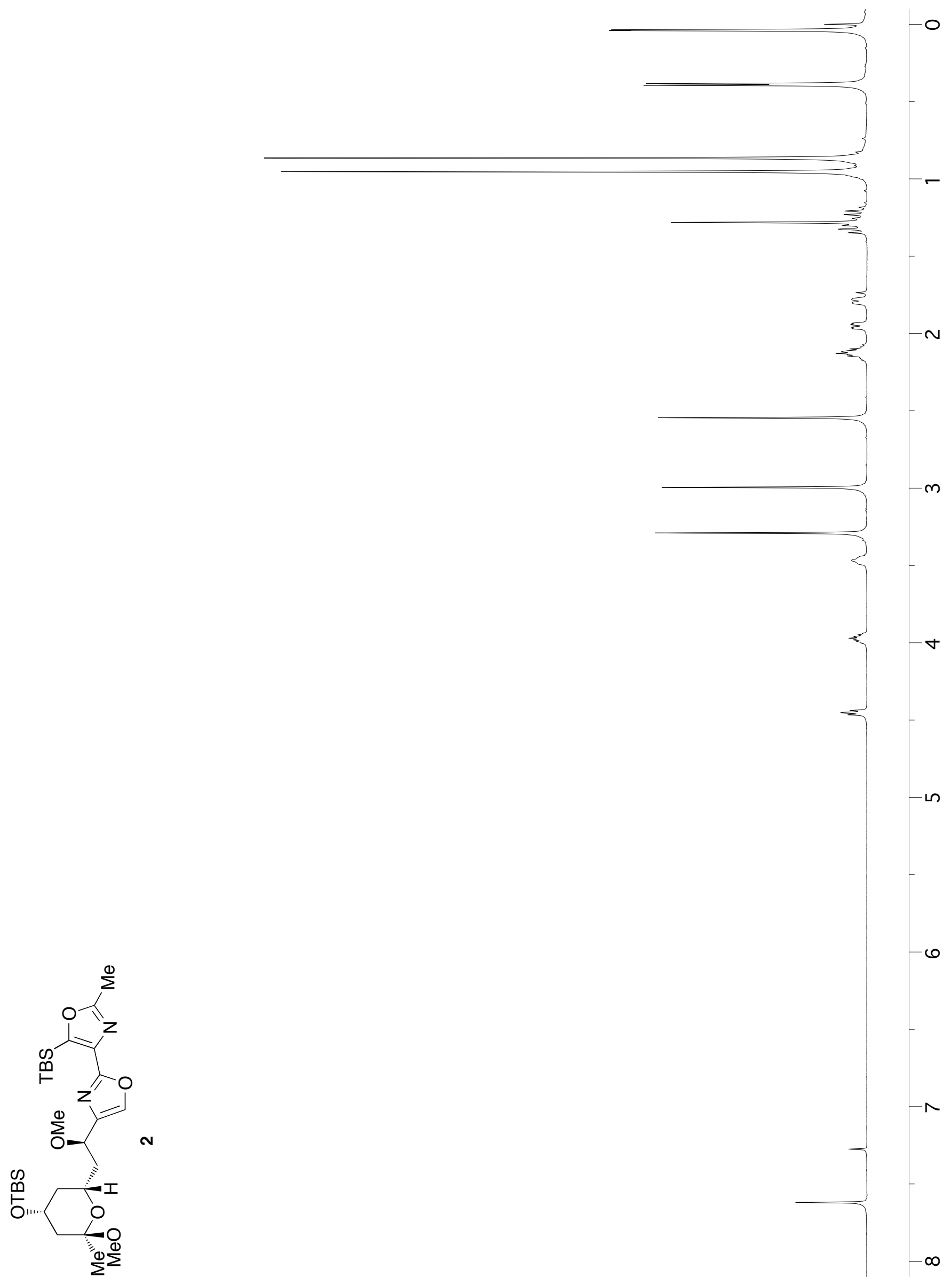




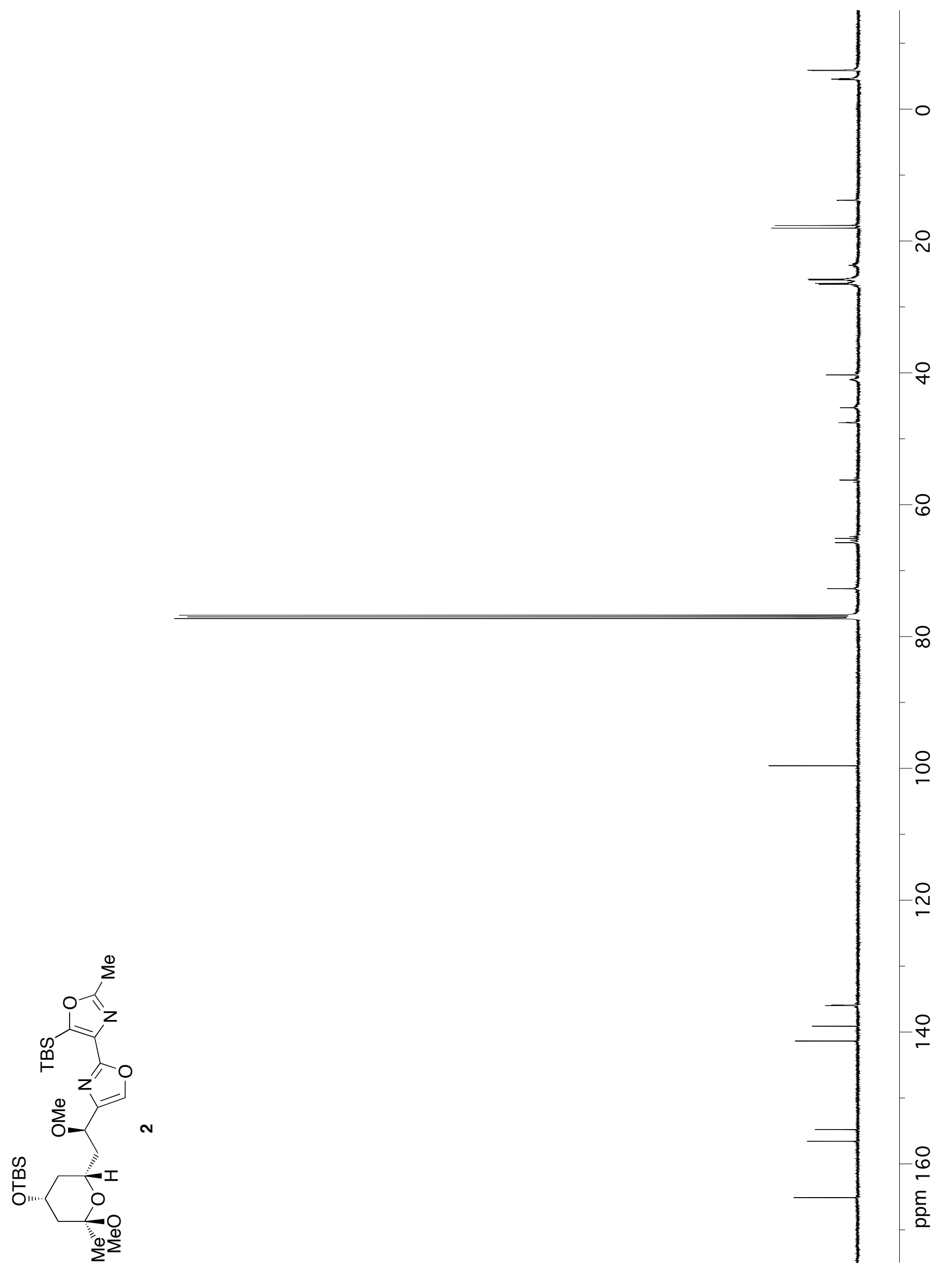




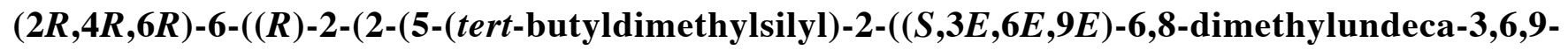
trienyl)oxazol-4-yl)oxazol-4-yl)-2-methoxyethyl)-tetrahydro-2-methoxy-2-methyl-2H-pyran-4-ol, tert-butyldimethylsilyl ether (12)

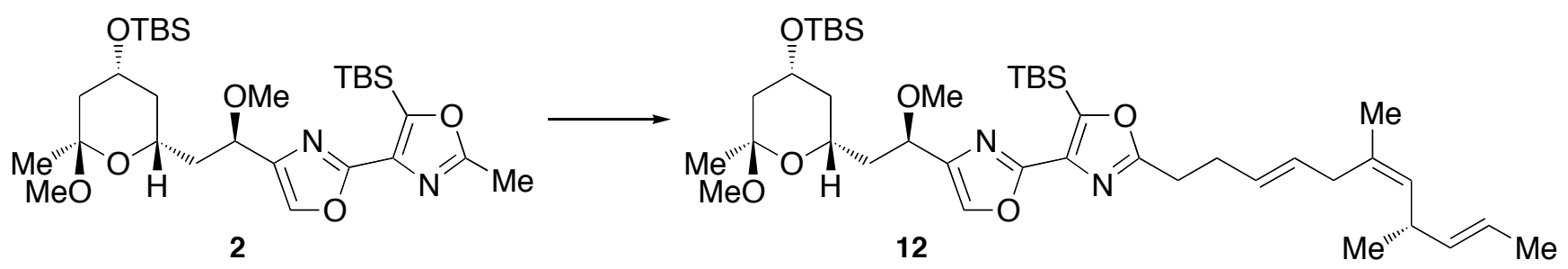

A $0.5 \mathrm{M}$ solution of $\mathrm{LiNEt}_{2}$ was prepared by addition of $n \mathrm{BuLi}(1.00 \mathrm{~mL}$ of a $2.72 M$ solution in hexanes, $2.72 \mathrm{mmol})$ to $25 \mathrm{~mL}$ concentration flask containing diethylamine $(0.310 \mathrm{~mL}, 3.00 \mathrm{mmol})$ in THF $(4.13 \mathrm{~mL})$ at $-78{ }^{\circ} \mathrm{C}$ under an atmosphere of argon. After 5 min, the flask was warmed to $0{ }^{\circ} \mathrm{C}$. Mixed methyl acetal $2(69.0 \mathrm{mg}, 0.119 \mathrm{mmol}, 1.0$ equiv) in a $10 \mathrm{~mL}$ concentration flask was diluted with THF $(2.0 \mathrm{~mL})$. The solution was cooled to $-78{ }^{\circ} \mathrm{C}$ under an atmosphere of argon and the $\mathrm{LiNEt}_{2}$ prepared above was added dropwise until a yellow color persisted (to remove any adventitious acid source-about 4 drops). After this zero point, LiNEt $_{2}(0.285 \mathrm{~mL}$ of a $0.5 \mathrm{M}$ solution in THF, 0.143 mmol, 1.2 equiv) was added dropwise via gastight syringe. The reaction took on an bright orange/red color. After stirring at $-78{ }^{\circ} \mathrm{C}$ for $15 \mathrm{~min}$, allylic bromide $\mathbf{3}$ (31.8 $\mathrm{mg}, 0.131 \mathrm{mmol}, 1.1$ equiv) was added dropwise via cannula in THF $(1.65 \mathrm{~mL})$ causing the reaction to become progressively lighter orangeyellow. After $15 \mathrm{~min}$, the reaction was quenched with sat. aq. $\mathrm{NaHCO}_{3}(5 \mathrm{~mL})$, diluted with EtOAc (5 $\mathrm{mL}$ ) and warmed to rt. The layers were separated and the aqueous phase was further extracted with EtOAc $(3 \times 5 \mathrm{~mL})$. The combined organics were dried over anhydrous $\mathrm{Na}_{2} \mathrm{SO}_{4}$, filtered, and concentrated in vacuo. his material was purified via automated silica column chromatography $(0 \rightarrow 20 \%$ EtOAc/hexanes, TLC: $\mathrm{R}_{\mathrm{f}}=0.62$ in $30 \%$ EtOAc/hexanes) to provide protected hennoxazole $12(67.7 \mathrm{mg}$, $77 \%$ yield) as a clear colorless oil along with unreacted starting material $(4.6 \mathrm{mg}, 7 \%)$ and doublyalkyated product $(6.1 \mathrm{mg}, 6 \%):{ }^{1} \mathrm{H}$ NMR $\left(500 \mathrm{MHz}, \mathrm{CDCl}_{3}\right) \delta 7.62(\mathrm{~s}, 1 \mathrm{H}), 5.51-5.38(\mathrm{~m}, 2 \mathrm{H}), 5.38$ $-5.31(\mathrm{~m}, 2 \mathrm{H}), 4.99(\mathrm{~d}, 1 \mathrm{H}, J=9.2 \mathrm{~Hz}), 4.45(\mathrm{dd}, 1 \mathrm{H}, J=8.1,6.0 \mathrm{~Hz}$ ), 3.97 (dddd, $J=10.8,10.8,4.7$, $4.7 \mathrm{~Hz}, 1 \mathrm{H}), 3.49-3.42(\mathrm{~m}, 1 \mathrm{H}), 3.28(\mathrm{~s}, 3 \mathrm{H}), 3.04-2.95(\mathrm{~m}, 1 \mathrm{H}), 3.00(\mathrm{~s}, 3 \mathrm{H}), 2.92(\mathrm{t}, J=7.6 \mathrm{~Hz}, 2 \mathrm{H})$, $2.71(\mathrm{dd}, J=14.3,6.1 \mathrm{~Hz}, 1 \mathrm{H}), 2.66(\mathrm{dd}, J=14.3,6.1 \mathrm{~Hz}, 1 \mathrm{H}), 2.51(\mathrm{dt}, J=7.2,6.7 \mathrm{~Hz}, 2 \mathrm{H}), 2.18-2.07$ (m, 2H), 1.95 (ddd, $1 \mathrm{H}, J=12.8,4.7,1.5 \mathrm{~Hz}), 1.97(\mathrm{ddt}, J=12.3,4.7,2.4 \mathrm{~Hz}, 1 \mathrm{H}), 1.63(\mathrm{~d}, J=4.0 \mathrm{~Hz}$, $3 \mathrm{H}), 1.60(\mathrm{~d}, J=1.4 \mathrm{~Hz}, 3 \mathrm{H}), 1.34(\mathrm{dd}, J=12.6,11.1 \mathrm{~Hz}, 1 \mathrm{H}), 1.28$ (s, 3H), 1.22 (ddd, J =11.8, 11.8, $11.8 \mathrm{~Hz}, 1 \mathrm{H}), 0.98(\mathrm{~d}, J=6.7 \mathrm{~Hz}, 3 \mathrm{H}), 0.95(\mathrm{~s}, 9 \mathrm{H}), 0.86(\mathrm{~s}, 9 \mathrm{H}), 0.39$ (s, 3H), 0.38 (s, 3H), $0.04(\mathrm{~s}, 3 \mathrm{H})$, 0.03 (s, 3H) ppm; ${ }^{13} \mathrm{C}$ NMR $\left(125 \mathrm{MHz}, \mathrm{CDCl}_{3}\right) \delta$ 168.0, 156.6, 154.7, 141.3, 139.0, 136.1, 136.0, 132.0, $130.4,129.5,128.7,122.5,99.6,72.7,65.7,65.1,56.3,47.6,45.3,41.0,40.3,35.3,35.2,30.0,28.2$, 26.5, 25.8, 23.7, 23.3, 21.4, 18.0, 17.9, 17.6, -4.6, -5.9 ppm; IR (film) 2929, 2857, 1612, 1463, 1376, $1252,1192,1086,969,838,778,621,525,506,489 \mathrm{~cm}^{-1} ;[\alpha]_{\mathrm{D}^{25}}=-40.3^{\circ}\left(c=1.01, \mathrm{CHCl}_{3}\right) ; \mathrm{HRMS}$ (CI): Exact mass calcd for $\mathrm{C}_{41} \mathrm{H}_{70} \mathrm{~N}_{2} \mathrm{O}_{6} \mathrm{Si}_{2} \mathrm{Li}[\mathrm{M}+\mathrm{Li}]^{+}:$749.4933; Found: 749.4917 . 


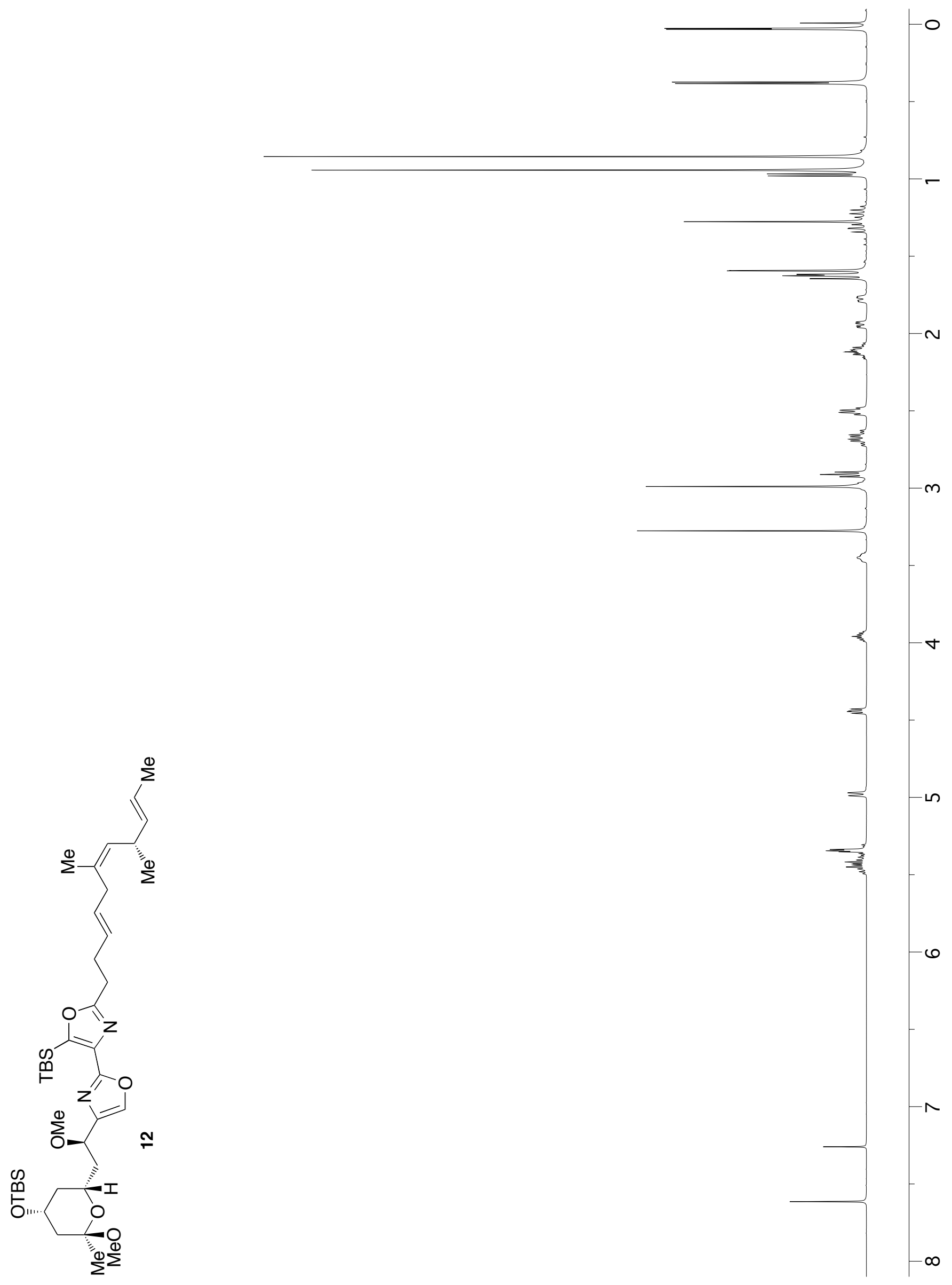




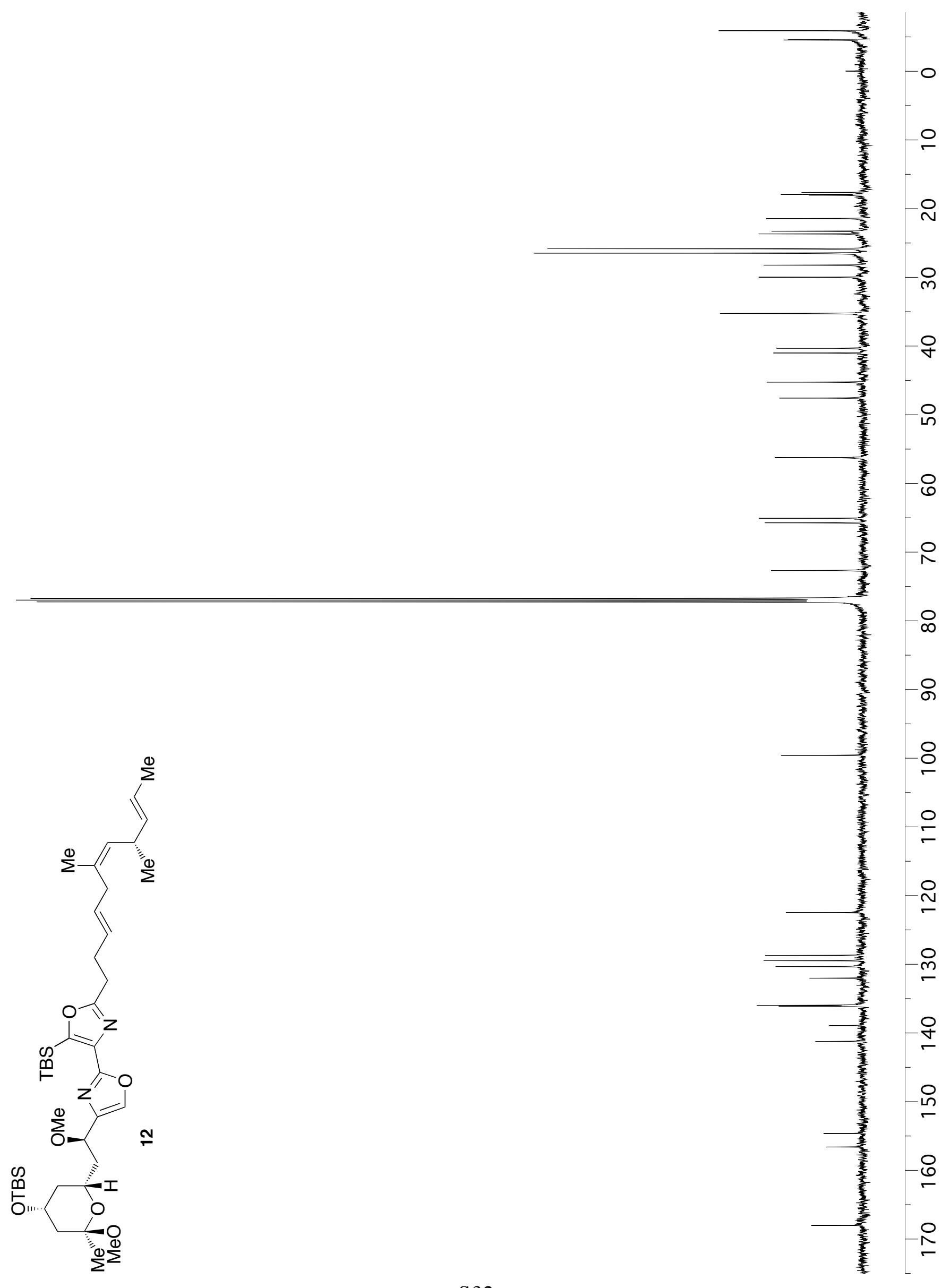




\section{Hennoxazole A (1)}

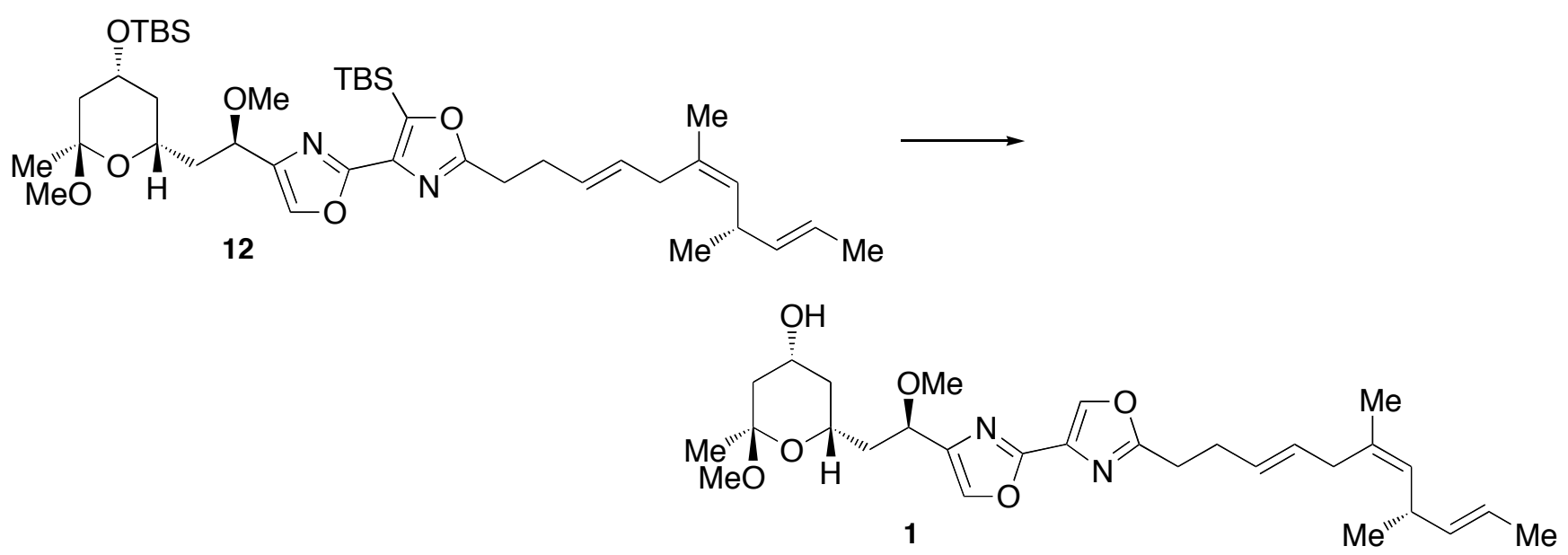

To a $25 \mathrm{~mL}$ flask containing protected hennoxazole $12(67.7 \mathrm{mg}, 0.091 \mathrm{mmol}, 1.0$ equiv) in THF (6.0 $\mathrm{mL})$ under $\operatorname{Ar}(\mathrm{g})$ was added TBAF $(547 \mu \mathrm{L}$ of a $1.0 \mathrm{M}$ solution in THF, $0.547 \mathrm{mmol}, 6$ equiv). The solution was stirred for $24 \mathrm{hr}$, after which, the reaction was concentrated in vacuo and purified via flash chromatography $\left(0 \% \rightarrow 100 \%\right.$ EtOAc, TLC: $\mathrm{R}_{\mathrm{f}}=0.27$ in $80 \%$ EtOAc/hexanes) to provide hennoxazole, 1 (46.2 mg, 99\% yield) as a clear colorless oil: ${ }^{1} \mathrm{H}$ NMR $\left(500 \mathrm{MHz}, \mathrm{CDCl}_{3}\right) \delta 8.13(\mathrm{~s}, 1 \mathrm{H}), 7.63(\mathrm{~s}, 1 \mathrm{H})$, 5.50-5.38 (m, 2H), 5.37-5.31 (m, 2H), $4.99(\mathrm{~d}, 1 \mathrm{H}, J=9.2 \mathrm{~Hz}), 4.45(\mathrm{t}, 1 \mathrm{H}, J=7.1 \mathrm{~Hz}), 4.04$ (dddd, $J=$ 10.8, 10.8, 4.5, 4.5 Hz, 1H), 3.61-3.54 (m, 1H), $3.31(\mathrm{~s}, 3 \mathrm{H}), 3.07(\mathrm{~s}, 3 \mathrm{H}), 3.03-2.95(\mathrm{~m}, 1 \mathrm{H}), 2.90(\mathrm{t}$, $2 \mathrm{H}, J=7.6 \mathrm{~Hz}), 2.71(\mathrm{dd}, J=14.4,6.5 \mathrm{~Hz}, 1 \mathrm{H}), 2.66(\mathrm{dd}, J=14.4,6.0 \mathrm{~Hz}, 1 \mathrm{H}), 2.51(\mathrm{dt}, J=7.2,6.7$ $\mathrm{Hz}, 2 \mathrm{H}), 2.22-2.15(\mathrm{~m}, 1 \mathrm{H}), 2.11-2.03(\mathrm{~m}, 2 \mathrm{H}), 1.97$ (ddt, $J=12.3,4.7,2.2 \mathrm{~Hz}, 1 \mathrm{H}), 1.70$ (br s, $1 \mathrm{H})$, $1.63(\mathrm{dd}, J=4.7,1.0 \mathrm{~Hz}, 3 \mathrm{H}), 1.61(\mathrm{~d}, J=1.2 \mathrm{~Hz}, 3 \mathrm{H}), 1.32(\mathrm{~s}, 3 \mathrm{H}), 1.31(\mathrm{dd}, J=12.4,11.1 \mathrm{~Hz}, 1 \mathrm{H})$, $1.22(\mathrm{ddd}, J=11.6,11.6,11.6 \mathrm{~Hz}, 1 \mathrm{H}), 0.98(\mathrm{~d}, J=6.9 \mathrm{~Hz}, 3 \mathrm{H}) \mathrm{ppm}$.; ${ }^{1} \mathrm{H}$ NMR $(500 \mathrm{MHz}$, acetone-d 6$)$ $\delta 8.41(\mathrm{~s}, 1 \mathrm{H}), 8.00(\mathrm{~s}, 1 \mathrm{H}), 5.53(\mathrm{dt}, J=15.2,6.6 \mathrm{~Hz}, 1 \mathrm{H}), 5.44(\mathrm{dt}, J=15.3,6.4 \mathrm{~Hz}, 1 \mathrm{H}), 5.39-5.29$ $(\mathrm{m}, 2 \mathrm{H}), 4.95(\mathrm{~d}, 1 \mathrm{H}, J=9.4 \mathrm{~Hz}), 4.46(\mathrm{dd}, 1 \mathrm{H}, J=8.1,6.2 \mathrm{~Hz}), 3.92-3.84(\mathrm{~m}, 1 \mathrm{H}), 3.67(\mathrm{~d}, J=5.0 \mathrm{~Hz}$, $1 \mathrm{H}), 3.54-3.47(\mathrm{~m}, 1 \mathrm{H}), 3.22(\mathrm{~s}, 3 \mathrm{H}), 3.02(\mathrm{~s}, 3 \mathrm{H}), 3.05-2.97(\mathrm{~m}, 1 \mathrm{H}), 2.89(\mathrm{t}, 2 \mathrm{H}, J=7.4 \mathrm{~Hz}), 2.74-2.64$ $(\mathrm{m}, 2 \mathrm{H}), 2.50(\mathrm{dt}, J=7.2,6.7 \mathrm{~Hz}, 2 \mathrm{H}), 2.11-2.00(\mathrm{~m}, 2 \mathrm{H}), 1.97(\mathrm{ddd}, J=12.4,4.7,1.5 \mathrm{~Hz}, 1 \mathrm{H}), 1.88$ (ddt, $J=12.3,4.5,2.3 \mathrm{~Hz}, 1 \mathrm{H}), 1.59(\mathrm{~s}, 3 \mathrm{H}), 1.58(\mathrm{~s}, 3 \mathrm{H}), 1.24(\mathrm{~s}, 3 \mathrm{H}), 1.22(\mathrm{dd}, \mathrm{J}=12.3,11.3 \mathrm{~Hz}, 1 \mathrm{H})$, 1.10 (ddd, $J=11.7,11.7,11.7 \mathrm{~Hz}, 1 \mathrm{H}), 0.95(\mathrm{~d}, J=6.9 \mathrm{~Hz}, 3 \mathrm{H}) \mathrm{ppm} .{ }^{13} \mathrm{C} \mathrm{NMR}\left(125 \mathrm{MHz}, \mathrm{CDCl}_{3}\right) \delta$ 165.6, 155.6, 141.8, 138.1, 136.1, 135.8, 132.0, 130.4, 130.3, 129.7, 128.4, 122.5, 99.5, 72.9, 65.8, 64.6, 56.5, 47.7, 44.9, 40.5, 40.3, 35.2, 29.9, 28.2, 23.6, 23.3, 17.9 ppm. ${ }^{13} \mathrm{C}$ NMR (125 MHz, acetone-d 6$) \delta$ $166.0,156.3,142.2,139.5,137.6,136.9,132.6,131.3,130.9,130.0,129.6,122.8,100.0,73.1,66.4$, 64.2, 56.0, 47.7, 45.8, 41.5, 41.3, 35.8, 35.7, 30.2, 28.5, 23.9, 23.3, 21.6, 17.9 ppm; IR (film) 3401, 2958, 2929, 1632, 1579, 1449, 1375, 1229, 1189, 1108, 1048, 1025, 969, 917, 830, $774 \mathrm{~cm}^{-1} ;[\alpha]_{\mathrm{D}^{25}}=$ $-46.8^{\circ}\left(c=0.635, \mathrm{CHCl}_{3}\right)$; HRMS (CI): Exact mass calcd for $\mathrm{C}_{29} \mathrm{H}_{42} \mathrm{~N}_{2} \mathrm{O}_{6} \mathrm{Li}[\mathrm{M}+\mathrm{Li}]^{+}$: 521.3203; Found: 521.3185 . 


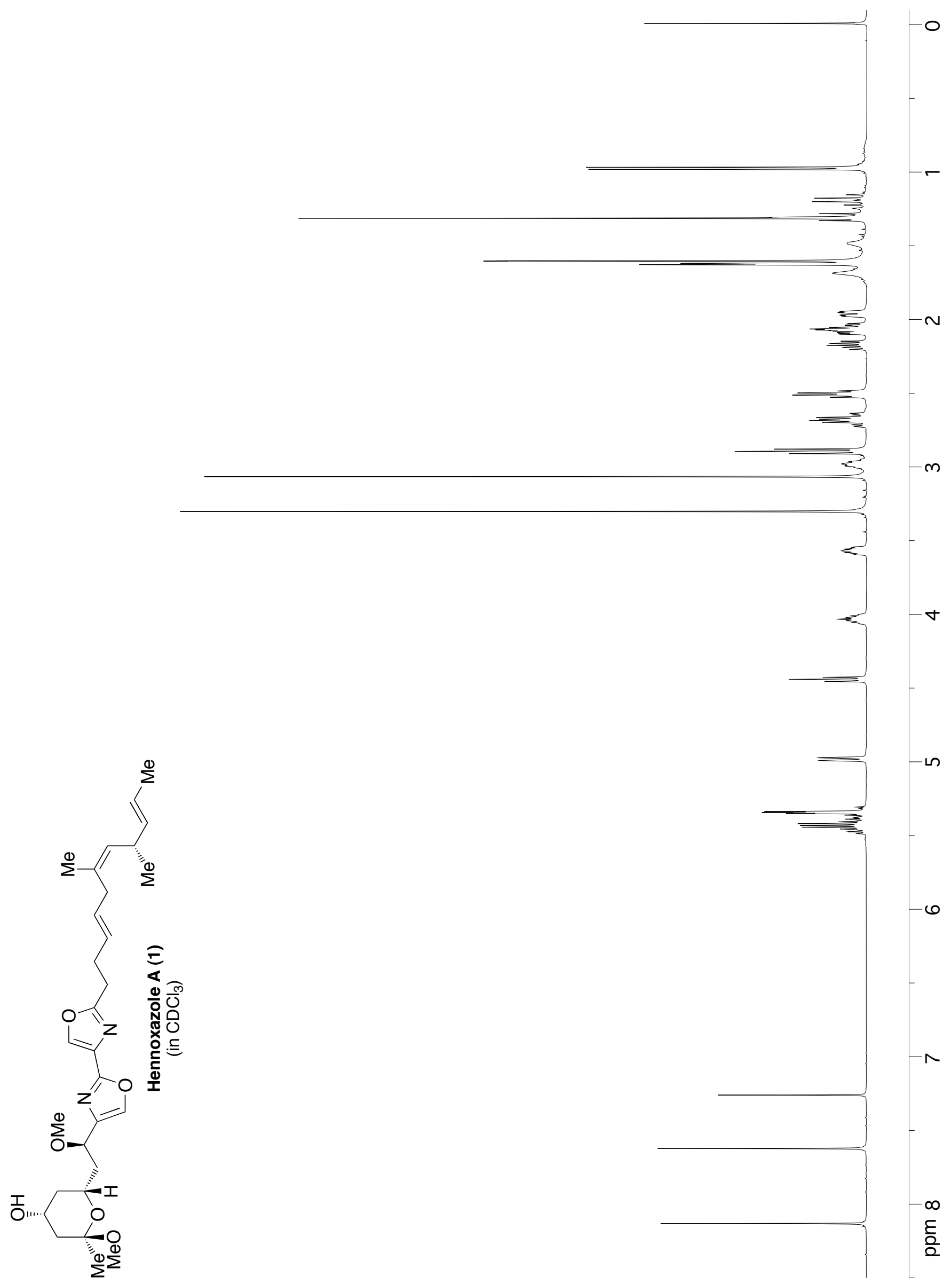




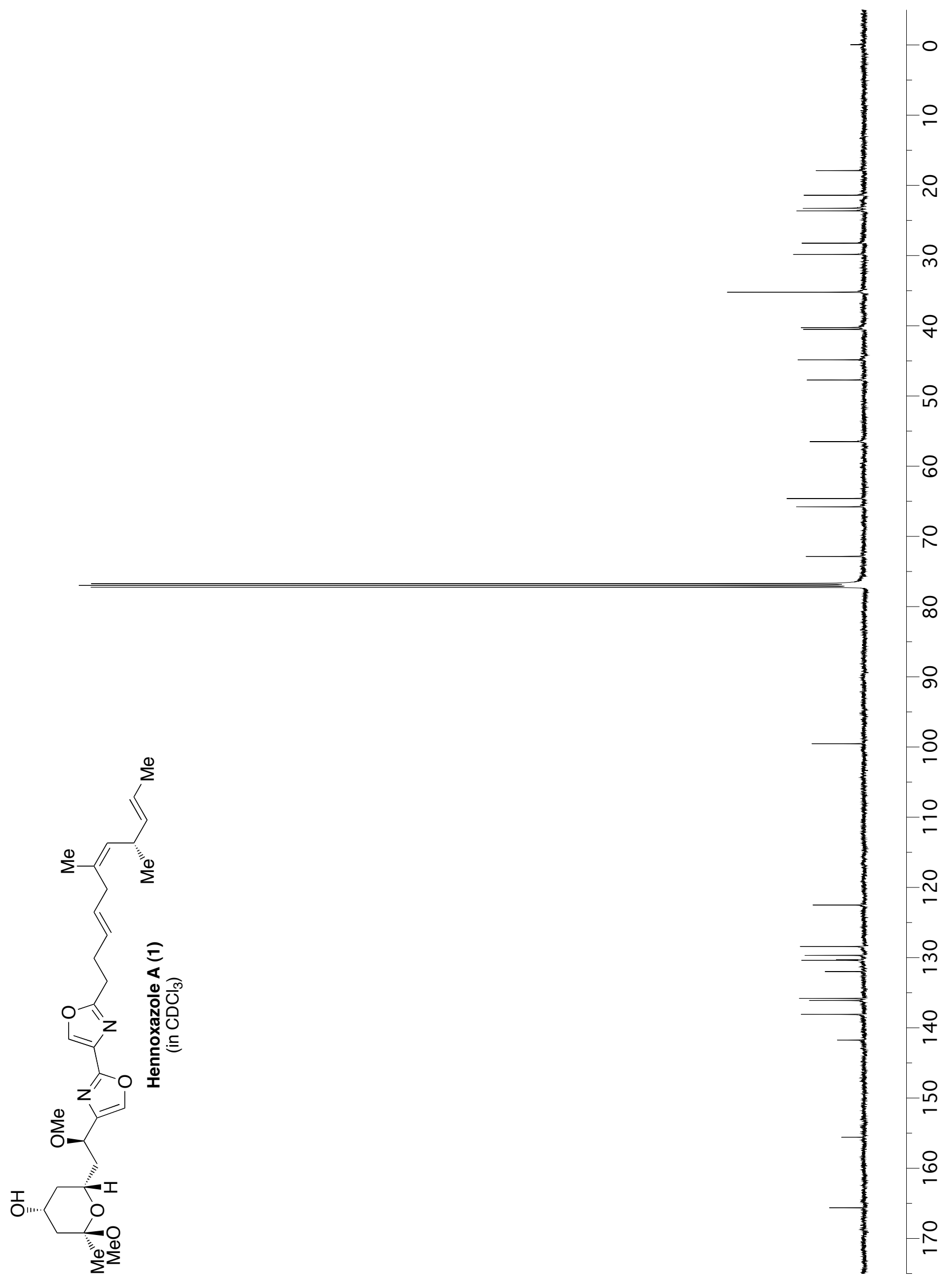




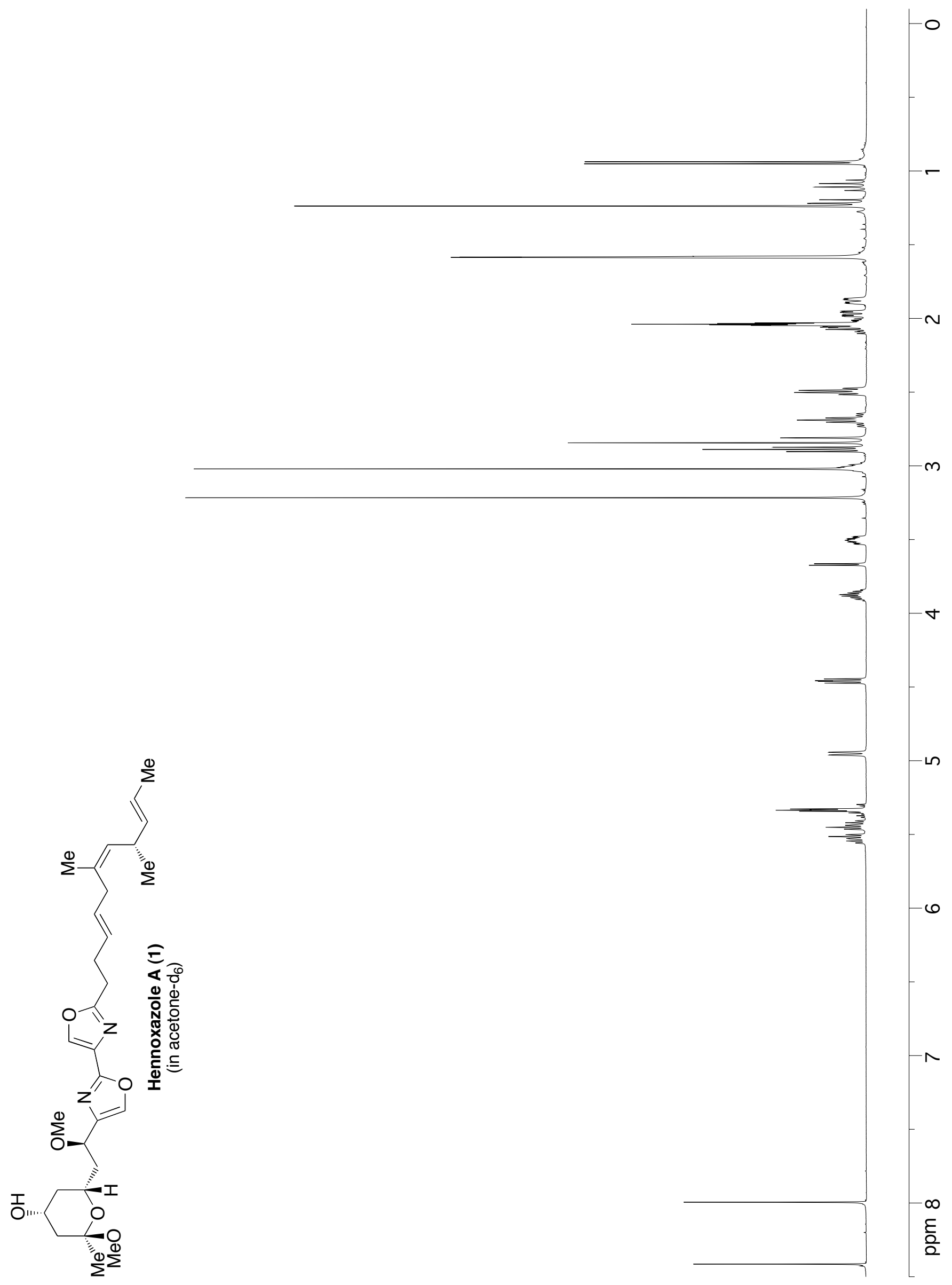




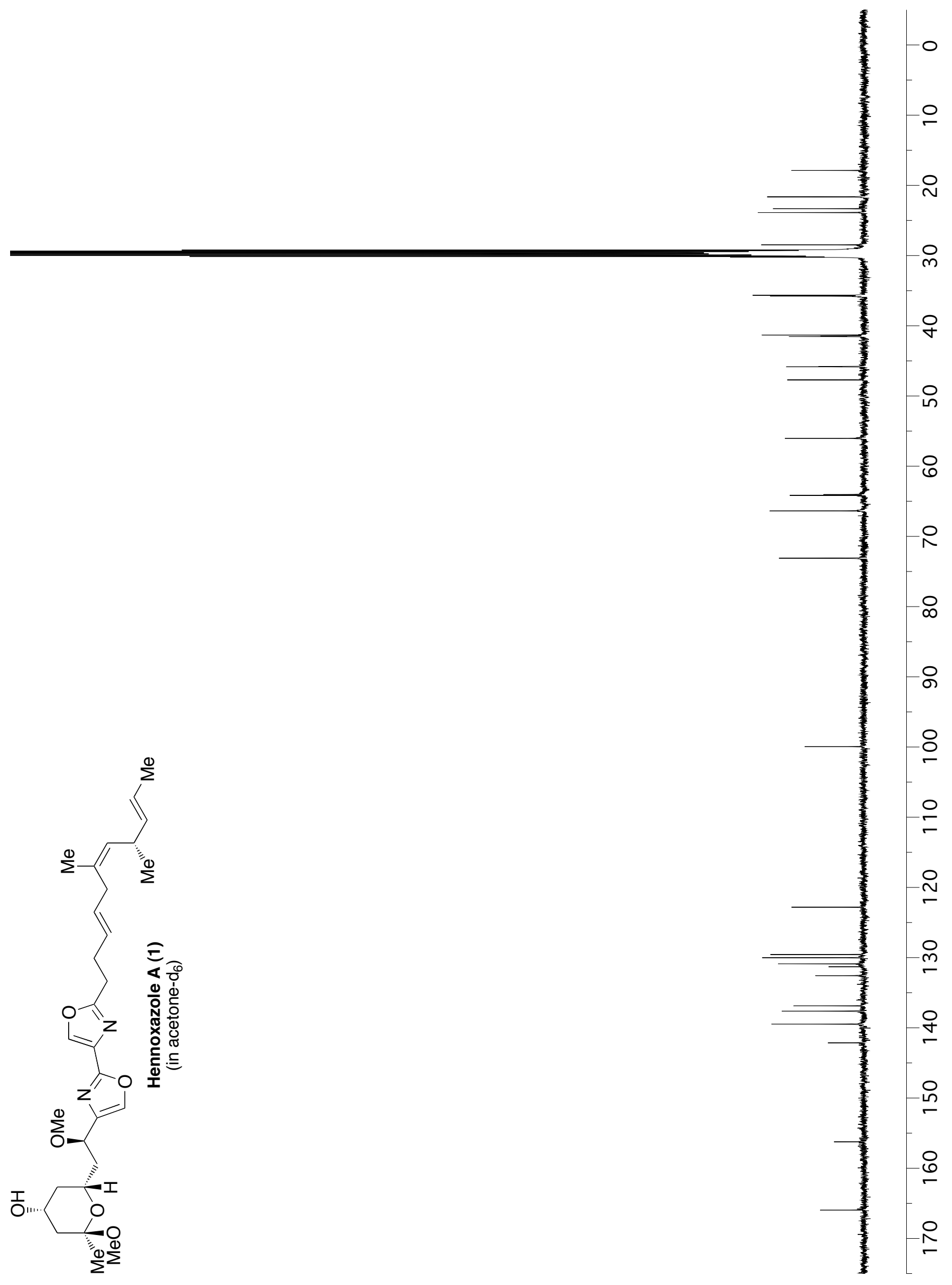

